Published in final edited form as:

Mol Pharm. 2016 October 03; 13(10): 3381-3394. doi:10.1021/acs.molpharmaceut.6b00288.

\title{
Reduction Sensitive PEG Hydrogels for Codelivery of Antigen and Adjuvant To Induce Potent CTLs
}

\author{
Chintan H. Kapadia ${ }^{\dagger}$, Shaomin Tian ${ }^{\ddagger}$, Jillian L. Perry ${ }^{\S}$, J. Christopher Luft ${ }^{\dagger}$, and Joseph M. \\ DeSimone ${ }^{\dagger, \ddagger, \|, \perp, \#,{ }^{*}}$ \\ tDivision of Molecular Pharmaceutics, Eshelman School of Pharmacy, University of North \\ Carolina, Chapel Hill, North Carolina 27599, United States \\ ¥Department of Microbiology and Immunology, University of North Carolina, Chapel Hill, North \\ Carolina 27599, United States \\ $\S$ Lineberger Comprehensive Cancer Center, University of North Carolina, Chapel Hill, North \\ Carolina 27599, United States \\ "Department of Chemistry, University of North Carolina, Chapel Hill, North Carolina 27599, United \\ States \\ ${ }^{\perp}$ Department of Chemical and Biomolecular Engineering, NC State University, Raleigh, North \\ Carolina 27695, United States \\ \#Sloan-Kettering Institute for Cancer Research, Memorial Sloan-Kettering Cancer Center, New \\ York, New York 10021, United States
}

\section{Abstract}

Educating our immune system via vaccination is an attractive approach to combat infectious diseases. Eliciting antigen specific cytotoxic T cells (CTLs), CD8 ${ }^{+}$effector T cells, is essential in controlling intracellular infectious diseases such as influenza (Flu), tuberculosis (TB), hepatitis, and HIV/AIDS, as well as tumors. However, vaccination utilizing subunit peptides to elicit a potent $\mathrm{CD} 8^{+} \mathrm{T}$ cell response with antigenic peptides is typically ineffective due to poor immunogenicity. Here we have engineered a reduction sensitive nanoparticle (NP) based subunit vaccine for intracellular delivery of an antigenic peptide and immunostimulatory adjuvant. We have co-conjugated an antigenic peptide (ovalbumin-derived CTL epitope [OVA 257-264: SIINFEKL]) and an immunostimulatory adjuvant (CpG ODNs, TLR9 agonist) to PEG hydrogel NPs via a reduction sensitive linker. Bone-marrow derived dendritic cells (BMDCs) treated with the SIINFEKL conjugated NPs efficiently cross-presented the antigenic peptide via MHC-I surface receptor and induced proliferation of OT-I T cells. CpG ODN-conjugated NPs induced maturation of BMDCs as evidenced by the overexpression of CD80 and CD40 costimulatory

\footnotetext{
*Corresponding Author: desimone@unc.edu.

The authors declare the following competing financial interest(s): Joseph M. DeSimone is a founder of and maintains a financial interest in Liquidia Technologies. Liquidia was founded in 2004 to commercialize PRINT technology and other discoveries of Professor Joseph DeSimone and colleagues at the University of North Carolina, Chapel Hill.

Supporting Information

The Supporting Information is available free of charge on the ACS Publications website at DOI: 10.1021/acs.molpharmaceut.6b00288. Physical characterization of conjugated NPs, T-cell proliferation assay, and data on IFN- $\gamma$ producing T cells (PDF)
} 
receptors. Moreover, codelivery of NP conjugated SIINFEKL and CpG ODN significantly increased the frequency of IFN- $\gamma$ producing $\mathrm{CD} 8^{+}$effector $\mathrm{T}$ cells in mice ( 6 -fold improvement over soluble antigen and adjuvant). Furthermore, the NP subunit vaccine-induced effector T cells were able to kill up to $90 \%$ of the adoptively transferred antigenic peptide-loaded target cell. These results demonstrate that the reduction sensitive NP subunit vaccine elicits a potent CTL response and provide compelling evidence that this approach could be utilized to engineer particulate vaccines to deliver tumor or pathogen associated antigenic peptides to harness the immune system to fight against cancer and infectious diseases.

\section{Graphical abstract}

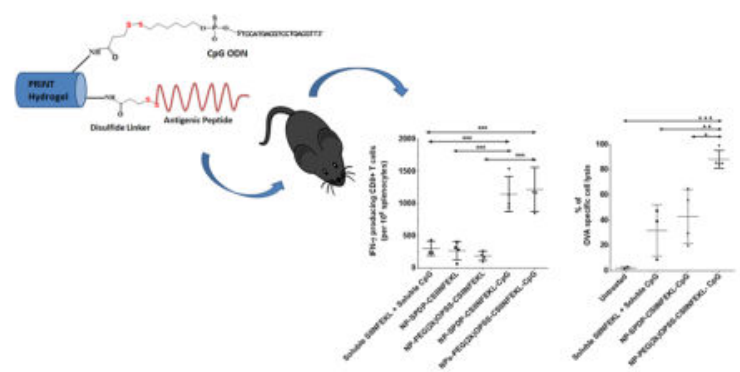

\section{Keywords}

nanoparticles; cancer vaccine; peptide vaccine; disulfide linkers; cytotoxic T cells (CTL)

\section{INTRODUCTION}

Vaccines are one of the major discoveries in modern medicine. Contributions include the almost complete elimination of polio, eradication of small pox, and a decrease by more than $95 \%$ of the incidence of diseases such as diphtheria, tetanus, pertussis, measles, mumps, and rubella. ${ }^{1}$ Vaccines have substantially decreased morbidity and mortality related to infectious disease and increased the average life span in the twenty-first century.

Despite these successes, there is a clear need to develop vaccines against pathogens like human immunodeficiency virus (HIV) and hepatitis $\mathrm{C}$ virus (HCV) and diseases such as malaria, tuberculosis, and cancer. Effective, traditional vaccines utilize live or attenuated pathogens which pose safety concerns due to the administration of unnecessary components of pathogenic microorganisms. ${ }^{2}$

New-generation subunit vaccines offer a safer and more specific approach to generate immunity, in which very specific components of pathogenic organisms (e.g., bacterial coat proteins, peptides, carbohydrates, or lipids; immunogenic determinants) are administered to protect against disease. Clinical success of subunit vaccines includes the use of Fluvirin (trivalent subunit protein) and Influvac (inactivated purified surface antigens from influenza virus) against influenza, BioThrax (AVA-anthrax adsorbed vaccine, contains no whole cell or live bacteria) against anthrax, and Cervarix (contains a mixture of human papilloma virus protein antigens with adjuvants alum and monophosphoryl lipid-A) against cervical cancer 
caused by HPV. ${ }^{3}$ Because of our improved understanding of the immune system, more specific and safer peptide epitopes are being designed based on recombinant technology and epitope focusing. ${ }^{4}$

Peptide antigens are easily synthesized, stored, and transported. Specific antigenic peptide epitopes can induce an antigen specific cytotoxic T cell (CTL) response, which is of the utmost importance in the elimination of intracellular pathogens, as well as cancer cells. Successful intracellular delivery of peptides to professional APCs (mostly dendritic cells [DCs]) and their cross-presentation to T cells elicit CTLs. For cross-presentation, APCs can process endocytosed antigens by either the classical (also cytosolic pathway) or vacuolar pathway. In the classical pathway, protein antigens are processed into 8 to 12 amino acid fragments by proteasomal degradation machinery in cytosol and loaded onto MHC-I molecules in the endoplasmic reticulum (ER) or phagosome by antigen processing machinery (APM). In the vacuolar pathway, degradation of pathogens/antigens and loading of peptide fragments to MHC-I occurs in the endosome. ${ }^{5}$ However, soluble peptides suffer from fast degradation half-life (from a few seconds to minutes depending on their length) ${ }^{6}$ and low cellular uptake, resulting in poor cross-presentation by DCs and lower immunogenicity.

Many particulate subunit vaccine delivery systems such as liposomes, nanobeads, solid-lipid nanoparticles, polymeric nanoparticle and micelles, etc. have been investigated as a delivery vehicle to induce protection against HIV, influenza, and cancer. ${ }^{7}$ Particulate carrier systems can improve immunogenicity of antigens and adjuvants by mimicking the size, shape, and/or surface molecule organization of pathogens, in order to facilitate uptake by APCs. ${ }^{8}$

Additionally they prevent enzymatic degradation of antigens/adjuvants, and facilitate their intracellular delivery by increasing their local resident time. ${ }^{9}$ Depending on their degradation mechanism, the antigen can be released into the late endosome/lysosome or into cytosol. By optimizing the polymeric material of the nanoparticulate carrier, release of antigen can be triggered by changes in an intracellular $\mathrm{pH},{ }^{10,11}$ slower degradation rate of biodegradable polymeric carrier, ${ }^{12-14}$ or enzyme mediated release of antigen such as endolysosomal lipases ${ }^{15}$ or $a$-chymotrypsin. ${ }^{16}$

Efficient activation of DCs as well as induction and proliferation of $\mathrm{T}$ cells also requires costimulatory signals which can be provided by delivering adjuvants. ${ }^{17}$ Codelivery of antigens with adjuvants using particulate carriers can further boost the immune response. ${ }^{18,19}$ Many immune stimulating agents such as alum, oil in water emulsions, various TLR/NLR agonists, etc. are being explored in clinical as well as preclinical studies as vaccine adjuvants. ${ }^{20}$ TLR agonists such as monophosphoryl lipid-A (MPL-A), CpG, resiquimod, poly I:C, etc. have been investigated in the development of particulate vaccines. ${ }^{4}$ Antigen and adjuvant can be encapsulated, adsorbed, or conjugated to NPs. Sarti et al. demonstrated induction of IgA titers via codelivery of encapsulated MPL-A and ovalbumin (OVA) through PLGA (poly(lactic-co-glycolic acid)) particles. ${ }^{21}$ De Titta et al. has shown generation of antigen specific $\mathrm{CD} 8^{+}$effector cells as well as memory cells in mice by delivering OVA protein and $\mathrm{CpG}$ conjugated particles via disulfide bond. ${ }^{22}$ Reversible cleavage and release of vaccine component can be made possible intracellularly 
by reduction of disulfide bond. Many others have also utilized disulfide linkers to design endosomal releasing nanovaccine carriers to induce in vivo CTL response. ${ }^{23-26}$

In this study, we have designed a PEG (polyethylene glycol) based PRINT (particle replication in nonwetting template) NP subunit vaccine to deliver a MHC-I epitope (SIINFEKL) of ovalbumin and a TLR-9 agonist, CpG oligonucleotide (ODN). PRINT offers the ability to mold biocompatible nanoparticles with complete control over particle size, shape, and chemical composition in a manner heretofore not possible with other particle technologies. High aspect ratio $(80 \times 80 \times 320 \mathrm{~nm}$, aspect ratio $=4)$ particles were chosen since the rod shape emulates known pathogens ${ }^{27}$ and increased aspect ratio is known to enhance cellular uptake. ${ }^{28}$ The antigenic peptide (CSIIN-FEKL) and adjuvant (CpG ODN) were surface conjugated to NPs through reduction sensitive linkers, taking advantage of the intracellular reducing environment to trigger their release. Two cleavable linkers were investigated, a short SPDP (succinimidyl 3-(2-pyridyldithio)propionate) linker, and long NHS-PEG(2k)-OPSS linker. SPDP has been widely used to conjugate amine groups to thiol groups for intracellular delivery of siRNA-polymer conjugates, ${ }^{29,30}$ aptamer toxins, aptamer virus capsid conjugates, ${ }^{31,32}$ delivery of siRNA or DNA, ${ }^{33-36}$ or delivery of model antigen ovalbumin via NPs. ${ }^{37-39}$ Though the NHS-PEG-OPSS linker has not been used as extensively in the literature, there is evidence to support the hypothesis that linker length is important. For example, Chen et al. showed higher immunostimulatory response with gold labeled CpG ODN by increasing the proximity of CpG ODN to gold nanoparticles. ${ }^{40}$ Furthermore, Singh et al. were able to demonstrate the effect of linker length on gene silencing efficiency of siRNA conjugated to quantum dots. ${ }^{41} \mathrm{We}$ therefore hypothesized that linker length would play a significant role in the accessibility of biomolecules to their appropriate receptors. Our work demonstrates the significant role that linker length plays in the development of particulate based subunit vaccines. Herein we report the formulation of highly uniform and monodisperse hydrogel PRINT NPs co-conjugated with SIINFEKL and $\mathrm{CpG}$, that are successfully taken up and processed by BMDCs, resulting in their efficient maturation and leading to SIINFEKL cross-presentation and subsequent induction of potent antigen-specific $\mathrm{T}$ cell proliferation and cytotoxic activity.

\section{MATERIALS AND METHODS}

\subsection{Materials}

Poly(ethylene glycol) diacrylate $\left(M_{\mathrm{n}} 700\right)\left(\mathrm{PEG}_{700} \mathrm{DA}\right), 2$-aminoethyl methacrylate hydrochloride (AEM), diphenyl (2,4,6-trimethylbenzoyl)-phosphine oxide (TPO), thiol modified CpG 1826 (C6-S-S-C6-tccatgacgttcctgacgtt), dithiothreitol (DTT), sucrose, and DNase, RNase free sterile water were purchased from Sigma-Aldrich. Tetraethylene glycol monoacrylate $\left(\mathrm{HP}_{4} \mathrm{~A}\right)$ was synthesized in house. Cysteine modified OVA $257-264$ (CSIINFEKL) were purchased from Peptide 2.0. Trifluoroacetic acid, methanol, dimethyl sulfoxide (DMSO), PTFE (polytetrafluoroethylene) syringe filters (13 mm membrane, 0.22$\mu \mathrm{m}$ pore size), HPLC grade water, and acetonitrile were obtained from Fisher Scientific. Conventional filters $(2 \mu \mathrm{m})$ were purchased from Agilent Technologies, and poly(vinyl alcohol) $\left(M_{\mathrm{w}} 2000\right)(\mathrm{PVOH})$ was purchased from Acros Organics. $N$-Succinimidyl 3-(2pyridyldithio)propionate (SPDP) was purchased from Thermo Scientific. Ortho- 
pyridyldisulfide-PEG- $N$-hydroxylsuccinimide ester (NHS-PEG (2k)-OPSS) was purchased from Creative PEGworks. PRINT molds $(80 \mathrm{~nm} \times 320 \mathrm{~nm})$ were obtained from Liquidia Technologies. DNA grade NAP-10 columns were purchased from GE Healthcare. RPMI1640 medium, penicillin and streptomycin, L-glutamine, and fetal bovine serum (FBS) were all from Life Technologies.

\subsection{Methods}

2.2.1. PRINT Nanoparticle Fabrication-The PRINT particle fabrication process is described previously. ${ }^{42}$ Briefly, the preparticle solution was prepared by dissolving 3.5 weight percent (wt/wt) of the various reactive monomers in isopropyl alcohol (IPA). The reactive monomers included a cure-site monomer (an oligomeric PEG with a nominal molar mass of $700 \mathrm{~g} / \mathrm{mol}$ terminally functionalized on both end groups with an acryl or acryloxy functionality); a hydrophilic monomer used to make up the majority of the particle composition (tetraethylene glycol monoacrylae, HP4A); an amine containing monomer (aminoethyl methacrylate, AEM) which provides a chemical handle to conjugate various linkers and peptides; and a photoinitiator, TPO. Preparticle solution was composed of $69 \mathrm{wt}$ $\% \mathrm{HP}_{4} \mathrm{~A}, 10$ wt $\% \mathrm{PEG}_{700} \mathrm{DA}, 20 \mathrm{wt} \% \mathrm{AEM}$, and 1 wt \% TPO. Using a \#3 Mayer rod, a thin film of preparticle solution was drawn onto corona-treated PET using roll-to-roll lab line (Liquidia Technologies) running at 12 feet per minute. The solvent was evaporated by heat guns. Then an $80 \times 80 \times 320 \mathrm{~nm}$, cylinder shaped mold was laminated to delivery sheet and passed through nip ( $80 \mathrm{psi}, 12$ feet per minute). After delamination, filled mold were cured by passing through a UV LED lamp ( $\lambda \max =395 \mathrm{~nm}, 30 \mathrm{psi}$ of $\mathrm{N}_{2}, 12$ feet per minute; Phoseon). Due to UV light initiated radical chain polymerization, monomers crosslinked into polymers to form a hydrogel. After cross-linking the hydrogels inside the mold cavities, the filled mold was laminated against a PVA harvesting sheet and passed through a heated nip $\left(140^{\circ} \mathrm{C}, 80 \mathrm{psi}, 12\right.$ feet per minute). Particles were removed from the mold by splitting the harvesting sheet from the mold. Particles were then harvested by dissolving a sacrificial harvesting layer of PVA into water $(2 \mathrm{~mL}$ of water per 10 feet of harvesting sheet). Particle suspensions were passed through $2 \mu \mathrm{m}$ filter to remove additional scum layer. To remove excess PVA, particles were spun down at 14,000 rpm (Eppendorf Thermomixer $\mathrm{R}$ ) for $25 \mathrm{~min}$, and resuspended into sterile water. This purification procedure was repeated 3 times.

2.2.2. Thermogravimetric Analysis-Concentrations of particles were determined by thermogravimetric analysis (TGA) using TA Instrument's Discovery TGA. Aluminum sample pans were tarred before loading the sample. $20 \mu \mathrm{L}$ of the stock nanoparticle solution was loaded onto the pan. Samples suspended in water were heated at $30{ }^{\circ} \mathrm{C} / \mathrm{min}$ to $130{ }^{\circ} \mathrm{C}$, followed by a $10 \mathrm{~min}$ isotherm at $130^{\circ} \mathrm{C}$. All samples were then cooled at $30^{\circ} \mathrm{C} / \mathrm{min}$ to $30{ }^{\circ} \mathrm{C}$, followed by a $2 \mathrm{~min}$ isotherm at $30^{\circ} \mathrm{C}$.

2.2.3. Scanning Electron Microscopy-Particles were visualized by scanning electron microscopy (SEM) using a Hitachi S-4700 SEM. Prior to imaging, SEM samples were coated with $1.5 \mathrm{~nm}$ of gold-palladium alloy using a Cressington 108 auto sputter coater. 
2.2.4. Dynamic Light Scattering-Particle size and zeta potential (ZP) were measured in sterile water by dynamic light scattering (DLS) on a Zetasizer Nano ZS (Malvern Instruments, Ltd.).

2.2.5. Conjugation of Linker to NPs-We utilized amine groups from AEM to conjugate cleavable linkers, SPDP and NHS-PEG(2k)OPSS. Theoretical numbers of $-\mathrm{NH}_{2}$ groups contributed from $1 \mathrm{mg}$ of nanoparticle suspension were calculated. Different molar ratios of linker to amine groups (such as $0.28,0.55$, and 2.30 ) were evaluated for the conjugation scheme (Table S1). For the optimized reaction scheme, particles were reacted with a 0.55 molar excess of linker, resulting in reacting $1 \mathrm{mg}$ of NPs with $0.24 \mathrm{mg}$ of SPDP or $6 \mathrm{mg}$ of NHS-PEG-OPSS in $1 \mathrm{~mL}$ of $1 \times$ PBS $+0.1 \%$ PVA for $2 \mathrm{~h}$. SPDP (or NHSPEG(2k)OPSS) was dissolved in DMF. The volume of DMF was kept constant at $160 \mu \mathrm{L}$ regardless of different linker mass used. Total volume of reaction was $1 \mathrm{~mL}$. NPs were continuously agitated for $2 \mathrm{~h}$ at $1400 \mathrm{rpm}$ (Eppendorf Thermomixer R). After $2 \mathrm{~h}$, unconjugated linker was removed from the pyridyldithiol decorated NPs via 2 centrifugation washes (Eppendorf Centrifuge 5417g) with sterile water. Efficiency of linker conjugation was evaluated by incubating $1 \mathrm{mg}$ of NPs in $1 \mathrm{~mL}$ of DTT solution. Moles of DTT used was 10 times higher than the moles of linkers added during the conjugation procedure. Due to disulfide exchange reaction, pyridine-2-thione is released from pyridyldithiol modified NPs, which can be detected by reading absorbance at $343 \mathrm{~nm}$ using Spectra Max M plate reader. Conjugation efficiency was determined by the following formula:

$$
\% \text { conjugation efficiency }=\frac{\text { amount of linker conjugated }}{\text { amount of linker changed }} \times 100
$$

Conjugation efficiency of linkers was between $50 \%$ and $60 \%$.

2.2.6. Conjugation of CSIINFEKL to NPs-Once NPs were modified with SPDP or NHS-PEG(2k)OPSS, they were spun down for $25 \mathrm{~min}$ at 14,000 rpm (Eppendorf Centrifuge $5417 \mathrm{~g}$ ) and resuspended into $800 \mu \mathrm{L}$ of sterile water. $1 \mathrm{mg} / \mathrm{mL}$ of cysteine labeled SIINFEKL (CSIINFEKL) solution was made in sterile water. $200 \mu \mathrm{L}$ of this solution was mixed with $800 \mu \mathrm{L}$ of NP suspension and incubated overnight. NPs were continuously agitated at $1400 \mathrm{rpm}$ (Eppendorf Thermomixer R). The following day, NPs were spun down for $25 \mathrm{~min}$ at 14,000 rpm (Eppendorf Centrifuge 5417g), supernatant was collected, and NPs were resuspended in $1 \mathrm{~mL}$ of sterile water. To remove unbound peptide, NPs were washed in sterile water 2 times. Due to disulfide exchange with cysteine labeled peptide, pyridine-2thione is released from pyridyl dithiol modified NPs. By reading the absorption of pyridine-2-thione in the supernatant at $343 \mathrm{~nm}$ using the Spectra Max M plate reader, the amount of pyridine-2-thione released from NPs can be calculated and thus the amount of peptide conjugated was evaluated. Conjugation efficiency of peptide was evaluated as mentioned by eq 1 . We found $60-70 \%$ conjugation efficiency of peptide to NPs.

\subsubsection{Reduction and Purification of C6-S-S-C6 CpG 1826-CpG 1826 with} phosphorothioate backbone was chosen because of slower in vivo degradation via nucleases as compared to $\mathrm{CpG}$ with phosphodiester. ${ }^{43}$ C6-S-S-C6 CpG 1826 was reduced with 100 
mM DTT solution in sodium phosphate buffer of $\mathrm{pH} 8.0$ and purified by gel filtration chromatography using Sephadex NAP-10 column. Unreduced CpG was kept for an hour in the presence of $100 \mathrm{mM}$ DTT solution in sodium phosphate buffer of $\mathrm{pH}$ 8.0. Sephadex NAP-10 column (DNA grade) was equilibrated by flowing through $15 \mathrm{~mL}$ of sterile water (DNase, RNase free). After equilibration, $0.75 \mathrm{~mL}$ of sample was loaded to column and allowed to pass through completely. Reduced $\mathrm{CpG}$ was eluted by passing through $1.2 \mathrm{~mL}$ of water. Concentration of $\mathrm{CpG}$ was measured by evaluating absorption at $260 \mathrm{~nm}$ by using a NanoDrop 2000 spectrophotometer.

2.2.8. Conjugation of Thiol-CpG 1826 to NPs-Once NPs were modified with SPDP or NHS-PEG(2k)OPSS, NPs were spun down for $25 \mathrm{~min}$ at 14,000 rpm (Eppendorf Centrifuge $5417 \mathrm{~g}$ ) and resuspended in $800 \mu \mathrm{L}$ of sterile water. $40 \mu \mathrm{g}$ of thiol CpG 1826 was mixed with $1 \mathrm{mg}$ of linker modified NPs and kept for 8 to $10 \mathrm{~h}$. Total volume of reaction was $1 \mathrm{~mL}$. NPs were continuously agitated at $1400 \mathrm{rpm}$ (Eppendorf Thermomixer R). Then NPs were spun down for $25 \mathrm{~min}$ at 14,000 rpm (Eppendorf Centrifuge 5417g) and resuspended in $200 \mu \mathrm{L}$ of $10 \times$ PBS. This washing procedure was repeated 3 times to remove adsorbed CpG. To evaluate conjugation of $\mathrm{CpG}$, NPs were incubated in $100 \mathrm{mM}$ DTT for $4 \mathrm{~h}$. NPs were spun down, and supernatant was collected. Conjugation efficiency of $\mathrm{CpG}$ was evaluated as mentioned by eq 1 . Evaluation of $\mathrm{CpG}$ was done by reading absorption at $260 \mathrm{~nm}$ using NanoDrop 2000 spectrophotometer. We found $70-80 \%$ conjugation efficiency of CpG to NPs.

2.2.9. Co-conjugation of CSIINFEKL and CpG ODN to NPs-CSIINFEKL peptide and $\mathrm{CpG}$ were co-conjugated in a 2 step process. For the co-conjugation process we used $0.39 \mathrm{mg}$ of SPDP or $12 \mathrm{mg}$ of NHS-PEG(2k)OPSS. After modification with linkers, NPs were conjugated to CSIINFEKL by incubating $1 \mathrm{mg}$ of NPs with $0.2 \mathrm{mg}$ of CSIINFEKL. Unbound peptides were removed by washing NPs in sterile water 2 times. After the final wash, nanoparticles were resuspended in $900 \mathrm{~mL}$ of sterile water and $0.04 \mathrm{mg}$ of reduced $\mathrm{CpG}$ was added and left to react for 8-10 h at $1400 \mathrm{rpm}$ (Eppendorf Thermomix R). After co-conjugation, to evaluate peptide and adjuvant loading, CSIINFEKL and CpG were cleaved from NPs by incubating $1 \mathrm{mg}$ of NPs with $100 \mathrm{mM}$ DTT for $4 \mathrm{~h}$. After $4 \mathrm{~h}$, nanoparticles were spun down at 14,000 rpm (Eppendorf Centrifuge 5417g) for $25 \mathrm{~min}$, and the supernatant was evaluated for released peptide and adjuvant through HPLC Agilent 1200 series and NanoDrop 2000 spectrophotometer, respectively. Co-conjugation of adjuvant resulted in a reduction of final peptide loading to $50 \%$ conjugation efficiency, while $\mathrm{CpG}$ loading remained at approximately $50-60 \%$ conjugation efficiency.

2.2.10. Peptide Evaluation via HPLC—Reverse phase high performance liquid chromatography (HPLC) was run on an Agilent 1200 series HPLC system using an Agilent C18 column. A Waters 2695 Alliance module equipped with quaternary pump, mobile phase degasser, temperature controlled auto sampler, and column thermostat were used for HPLC analysis. The separation was carried out on a Zorbax C18(2) column $(150 \mathrm{~mm} \times 4.6 \mathrm{~mm}$ i.d., $3 \mu \mathrm{m}$ particle size, $100 \AA$ A pore size) from Phenomenex (Torrance, CA) at column temperature of $50{ }^{\circ} \mathrm{C}$ and sample temperature of $50{ }^{\circ} \mathrm{C}$. Peptide was eluted using a mobile 
phase gradient, which consists of two solutions: solution A, water ( $0.1 \%$ TFA, trifluoroacetic acid), and solution $\mathrm{B}$, acetonitrile with $0.1 \%$ TFA. The gradient method is shown in Table 1 .

Binary linear gradients started from a mixture of $100 \% \mathrm{~A}$ and $0 \% \mathrm{~B}$ from 0 to $5 \mathrm{~min}$. From 5 to $25 \mathrm{~min} \mathrm{~B}$ was increased gradually from $0 \%$ to $95 \%$. Then, until 28 min the gradient was kept $5 \%$ for $\mathrm{A}$ and $95 \%$ for $\mathrm{B}$. The mobile phase composition was then changed back to initial solvent mixture, and the column was equilibrated for 2 min before every subsequent run. The flow rate of the mobile phase was set to $2.0 \mathrm{~mL} / \mathrm{min}$. The samples for HPLC injections were prepared by cleaving off peptide in $100 \mathrm{mM}$ DTT in sterile water. Peptides were detected via UV-vis detector at $210 \mathrm{~nm}$, and concentration was determined by comparing area of peak with standard curve. Know amounts of peptides were dissolved with $100 \mathrm{mM}$ DTT in sterile water to prepare a standard curve.

2.2.11. Animals-Female C57BL/6 mice and OT-I TCR transgenic mice were purchased from Jackson Laboratory and used at age 6-12 weeks. All experiments involving mice were carried out in accordance with an animal use protocol approved by the University of North Carolina Animal Care and Use Committee.

2.2.12. Preparation of Single Cell Culture from Mouse Spleens-Spleens were harvested from euthanized mice aseptically. Individual spleens were mechanically dissociated with the back of the sterile syringe plunger through a $100 \mu \mathrm{m}$ cell strainer into RPMI 1640 medium. Red blood cells were lysed by ACK buffer. Cells were then resuspended in R-10 medium (RPMI 1640 medium supplemented with 10\% FBS, $10 \mathrm{U} / \mathrm{mL}$ penicillin and $10 \mu \mathrm{g} / \mathrm{mL}$ streptomycin, $2 \mathrm{mM} \mathrm{L}$-Glutamine) and filtered through a $70 \mu \mathrm{m}$ cell strainer to remove any residual tissue fragments.

2.2.13. Preparation of BMDCs—Bone marrow was collected from mouse femurs and tibias as reported. ${ }^{44}$ Erythrocytes were lysed by ACK lysis buffer (Lonza). Bone marrow cells were then cultured at $2 \times 10^{6} / \mathrm{mL}$ in R10 supplemented with $50 \mu \mathrm{M} 2$-mercaptoethanol and $10 \mathrm{ng} / \mathrm{mL}$ each of IL-4 and granulocyte-macrophage-colony stimulating factor (GM$\mathrm{CSF}$ ). The culture was replenished with fresh medium on day 3 without removing old medium. On day 6 or 7, BMDCs were harvested and purified with Opti-Prep density medium (Sigma) to remove dead cells.

2.2.14. Antigen Presentation Assay in BMDCs-To evaluate the effect of linker length on antigen presentation, day 6 BMDCs $\left(3 \times 10^{5}\right.$ cells) were either untreated or treated with blank hydrogels (with and without linkers), CSIINFEKL ( $5 \mu \mathrm{g} / \mathrm{mL}$ ), CSIINFEKL conjugated to PEG hydrogels via SPDP (short cleavable linker, $5 \mu \mathrm{g} / \mathrm{mL}$ ), or CSIINFEKL conjugated to PEG hydrogels via PEG(2k)OPSS (longer cleavable linker $5 \mu \mathrm{g} / \mathrm{mL}$ ) for $4 \mathrm{~h}$. After $4 \mathrm{~h}$ incubation, cells were washed with PBS of $\mathrm{pH} \sim 7.4$ or citrate-phosphate buffer (pH 3.0) for $3 \mathrm{~min}$ on ice to strip off the MHC-I-peptide complex or NP-peptide/H-2K $\mathrm{K}^{\mathrm{b}}$ complex from cell surface. Additionally, cells were reincubated at $37^{\circ} \mathrm{C}$ for an additional $20 \mathrm{~h}$ postwashes and then stained with CD11c-APC and 25-D1.16-PE (anti-SIINFEKL/H-2K ${ }^{\mathrm{b}}$ complex) antibodies (eBioscience), followed by flow cytometry analysis on Cyan ADP (Dako). 
2.2.15. In Vitro $\mathrm{T}$ Cell Proliferation Assay-In vitro $\mathrm{CD} 8^{+} \mathrm{T}$ cell proliferation was done as previously reported. ${ }^{45}$ Briefly, day 6 BMDCs were dosed with the samples described ablove for $24 \mathrm{~h}$ at $37{ }^{\circ} \mathrm{C}$. OT-I CD $8{ }^{+} \mathrm{T}$ cells were isolated from OT-I mouse spleens using $\mathrm{CD} 8 \mathrm{a}^{+} \mathrm{T}$ cell Isolation Kit (Miltenyi Biotec) as per the manufacturer's instructions and labeled with CFSE $(5 \mu \mathrm{M})$ in PBS with $0.1 \%$ FBS for 10 min at $37^{\circ} \mathrm{C}$. BMDCs were then incubated with OT-I-CFSE cells in R-10 medium for $72 \mathrm{~h}$ at $37{ }^{\circ} \mathrm{C}$. After incubation, cells were stained with CD8 and Va2 antibodies. Division of OT-I cells as indicated by dilution of CFSE fluorescence in T cells was examined by flow cytometry.

2.2.16. Immunization Study-All formulations were prepared using low endotoxin grade reagents. To confirm the low endotoxin content of vaccines, formulations were routinely tested for endotoxin content using Pierce LAL Chromogenic Endotoxin Quantitation Kit following instructions. All formulations were prepared $24 \mathrm{~h}$ before injections, resuspended in an isotonic $9.25 \%$ sucrose, and subcutaneously administered in the right flank. SIINFEKL was given at a dose of $100 \mu \mathrm{g}$, and $\mathrm{CpG}$ was injected at a dose of $20 \mu \mathrm{g}$. On day 7, mice were sacrificed, and spleen and draining lymph nodes were harvested. All studies were repeated twice, and each experimental arm contained 4-6 mice.

2.2.17. ELISPOT Assay-Frequency of antigen specific IFN- $\gamma$ producing $T$ cells in spleen was evaluated using IFN- $\gamma$ ELISPOT kit (BD Biosciences). Immobilon-P hydrophobic PVDF plates (Millipore) were briefly treated with 35\% ethanol, washed 2 times with PBS, and coated overnight with anti-mouse IFN- $\gamma$ antibody at $4{ }^{\circ} \mathrm{C}$. The following day, plates were blocked with $200 \mu \mathrm{L}$ of R-10 medium with for $2 \mathrm{~h}$ at room temperature (RT). 100,000 splenocytes in R-10 medium were plated in each well, with or without restimulation with $10 \mu \mathrm{g} / \mathrm{mL}$ of SIINFEKL peptide overnight at $37^{\circ} \mathrm{C}$. Spots were then developed following the manufacturer's instructions.

2.2.18. In Vivo CTL Assay-In vivo CTL assay was performed as previously reported. ${ }^{46}$ Briefly, OT-I T cells were isolated from spleen using CD8 $a^{+} \mathrm{T}$ cell Isolation Kit (Miltenyi Biotec). C57BL/6 mice were injected intravenously with 10,000 OT-I T cells on day -1 . On day 0 , mice were either untreated or immunized subcutaneously with a mixture of soluble SIINFEKL and CpG ODN, or NPs-SPDP-CSIINFEKL-CpG, or NPs-PEG(2k)OPSSCSIINFEKL-CpG. Fifteen days after vaccination, mice were intravenously injected with $5 \times$ $10^{6}$ splenocytes as target cells. To prepare target cells, splenocytes from wild type C57BL/6 mice were pulsed with SIINFEKL peptide at $1 \mu \mathrm{g} / \mathrm{mL}$ in PBS for $1 \mathrm{~h}$ at $37 \mathrm{C}$, washed with PBS, and labeled with CSFE at $4 \mu \mathrm{M}$ in PBS for $10 \mathrm{~min}$ at $37^{\circ} \mathrm{C}\left(\mathrm{CFSE}^{\mathrm{hi}}\right)$; or non-peptide pulsed cells were labeled with CSFE at $0.4 \mu \mathrm{M}$ in PBS for $1 \mathrm{~h}$ at $37^{\circ} \mathrm{C}\left(\mathrm{CFSE}^{\mathrm{lo}}\right)$. CFSE ${ }^{\text {hi }}$ and $\mathrm{CFSE}^{\text {lo }}$ cells were mixed at 1:1 ratio to generate target cells for iv injections. On day 16, mice were euthanized, splenocytes were isolated, and cells were stained with anti-CD8 and $\mathrm{V} a 2$ antibodies. Percentages of CFSE ${ }^{\mathrm{hi}}$ and $\mathrm{CFSE}^{\mathrm{lo}}$ were determined with a flow cytometer. The ratio of unpulsed to pulsed target cells in the naive (unimmunized) mice defined the $0 \%$ lysis level. The percent-specific lysis is determined by loss of the antigen-pulsed CFSE ${ }^{\text {hi }}$ population compared with the unpulsed $\mathrm{CFSE}^{\mathrm{lo}}$ control population using the formula [1 (ratio in naive mouse/ratio in experimental mouse) $] \times 100$. 


\section{RESULTS AND DISCUSSION}

\subsection{Conjugation of CSIINFEKL and CpG to NPs}

Pathogen inspired cylinder shaped $(80 \times 80 \times 320 \mathrm{~nm})$ cationic PEG hydrogel NPs were fabricated by the PRINT process. It has been established that particles with a net positive charge bind to the negatively charged plasma membrane of the cell surface, thus increasing cellular uptake, as well as enhancing endosomal escape of cargos. ${ }^{47}$ Our previous work demonstrated that cationic hydrogel particles were able to efficiently deliver siRNA to cytosol, resulting in efficient gene silencing. ${ }^{48,49}$ Furthermore, Fromen et al. demonstrated significanlty higher lung and systemic antibody titers when cationic particles were used to deliver ovalbumin, as compared to anionic particles. ${ }^{50}$ Therefore, amine groups on the NP surface were used to conjugate cysteine labeled SIINFEKL peptide via reduction sensitive, heterobifunctional linkers SPDP or NHS-PEG(2k)OPSS in a two step-process (Figure 1). First, the succinimidyl ester of the linker was reacted to the amine groups on the particle, forming an amide bond. The excess linker was then removed via centrifugation washes, followed by reacting the cysteine labeled adjuvant with the pyridine disulfide ring. Linker density was controlled by varying the linker-to-NP ratio (Table S1), in an effort to determine maximum linker density while maintaining the positive charge of the nanoparticles. Thus, during monoconjugation or dual conjugation of antigenic peptide and $\mathrm{CpG}$, we aimed to keep the overall charge of NPs positive (as indicated by zeta potential) to facilitate better uptake by APCs and to get possible endosomal escape of cargos. As shown in Table S1, as the amount of SPDP charged to the nanoparticle increased from $0.12 \mathrm{mg}$ to $1 \mathrm{mg}$, the conjugated amount of linker increased; however, conjugation efficiency decreased. At the highest level of SPDP charged, the ZP of NPs became negative $(-21 \pm 2 \mathrm{mV})$ indicating almost complete conversion of amine groups and therefore eliminating this formulation from further development. The amount of SPDP and NHS-PEG(2k)OPSS used for single component conjugation (either peptide or $\mathrm{CpG}$ ) to modify $1 \mathrm{mg}$ of NPs was $0.24 \mathrm{mg}$ and 6 $\mathrm{mg}$, respectively, which resulted in positively charge particles.

Particles modified with each linker were then incubated overnight with CSIINFEKL in sterile water, resulting in peptide conjugation to the NPs via disulfide exchange, followed by incubation with thiol-containing $\mathrm{CpG}$ (Figure 1). For co-conjugation reactions, conjugation efficiency for peptide and $\mathrm{CpG}$ was around $50 \%$ and 50-60\%, respectively.

Following peptide and CpG modification, NPs remained highly uniform in size and shape as visualized by SEM (Figure 2). For all formulations the ZP remained greater than $+25 \mathrm{mV}$ (Table 2), which is desirable for cytosol delivery of antigens into MHC class I presentation pathway. Polydispersity index (PDI) of all sets of nanoparticles was found to be $<0.1$, which indicates monodisperse nanoparticles with homogeneous distribution, and size ranged from 250 to 280 depending on the surface modification.

\subsection{In Vitro Antigen Presentation in BMDCs by Subunit Vaccine}

In order for vaccines to generate an efficient $\mathrm{CD} 8^{+} \mathrm{T}$ cell response, $\mathrm{DCs}$ must first internalize antigens, process them into 8-12 amino acid peptides, and present them to $\mathrm{T}$ cell receptors as peptide/MHC-I complexes on the cell surface. T cells recognize MHC-I-peptide 
complex via $\mathrm{T}$ cell receptors and in the presence of other costimulatory signals subsequently proliferate. Since antigen presentation is key to developing an efficient $\mathrm{T}$ cell response, the antigen presentation efficiency of our PRINT NP subunit vaccine was evaluated using an in vitro assay. 25-D1.16, an antibody that recognizes SIINFEKL/H-2 $\mathrm{K}^{\mathrm{b}}$ on antigen presenting cells, was used to stain BMDCs treated with various samples to quantify antigen presentation. As expected, SIINFEKL peptide binds to $\mathrm{H}-2 \mathrm{~K}^{\mathrm{b}}$ on the cell surface directly upon $4 \mathrm{~h}$ pulsing, while treatment with blank NP-SPDP or NP-PEG(2k)OPSS and washes with PBS resulted in minimum staining for MHC-I-peptide complex (Figure 3A). Interestingly, cells treated with NP-SPDP-CSIINFEKL or NP-PEG(2k)OPSS-CSIINFEKL showed similar surface MHC-I-peptide staining to soluble peptide (Figure 3A and Supporting Figure 1I). When unbound peptide or NP-peptide was removed by washes with PBS, followed by another $20 \mathrm{~h}$ culture at $37^{\circ} \mathrm{C}$, it was observed that both NP-SPDPCSIINFEKL and NP-PEG(2k)OPSS-CSIINFEKL led to significantly higher pMHC level than that of soluble peptide pulsed BMDCs (Figure 3B and Supporting Figure 1J). On the other hand, pMHC complexes on soluble peptide pulsed and washed BMDCs decreased over time, suggesting loss of pMHC (Figure 3E). These results indicate that NP conjugation of antigenic peptide increases the overall level of cell surface pMHC over time, possibly due to enhanced cell uptake of NP-peptides and more efficient delivery of antigenic peptide into the class I presentation pathway.

To further examine the capability of delivering antigenic peptide into MHC class I presentation pathway by NP-peptide formulations, cells were pulsed with soluble or NP conjugated peptides for $4 \mathrm{~h}$, and washed with an acidic citrate-phosphate buffer (pH3.0) for 3 min to strip off the MHC-I peptide complex from the surface of the BMDCs. ${ }^{51}$ Cells were then incubated for another $20 \mathrm{~h}$ at $37^{\circ} \mathrm{C}$ allowing for internalized antigens to be represented onto cell surface. As shown in Figures 3C and 3F, citrate-phosphate treatment completely removed SIINFEKL from pMHC complexes for cells treated with soluble SIINFEKL (down to $0.9 \%$ ), but only partially removed cell bound NP-peptide (down to $\sim 50 \%$ ) (Supporting Figure $1 \mathrm{~K}$ ). This result may be due to the increased binding avidity of NP-peptide to cells as a result of the multivalence of peptide on the surface of NPs. As shown in Figure 3D, after acidic washes and an additional $20 \mathrm{~h}$ incubation, peptide/MHC I staining for NP-SPDPCSIINFEKL and NP-PEG(2k)OPSS-CSIINFEKL pulsed cells were $92.7 \%$ and $77 \%$, up from around 50\% (Figure 3G), which was also significantly higher than soluble SIINFEKL (6\%) (Supporting Figure 1L). During the reincubation period, cells treated with NP conjugated peptide had higher staining of pMHC complex, as compared to cells that did not go through a reincubation period (Figure 3G), which indicates higher uptake of NP and presentation of antigenic peptide. In conclusion, the conjugation of peptide to PRINT NPs via cleavable linkers is able to achieve not only higher but also longer lasting presentation of antigenic peptide by BMDCs as compared to soluble peptide.

\subsection{In Vitro Proliferation of OT-I T Cells in BMDCs Treated with Subunit Vaccine}

Next, we evaluated how cross presentation via BMDCs translated into activation and priming of $\mathrm{CD}^{+} \mathrm{T}$ cells. $\mathrm{CD} 8^{+} \mathrm{T}$ cells derived from OT-I TCR transgenic mice were used to evaluate OVA-specific $\mathrm{T}$ cell response for NP and soluble vaccine formulations. In this study, BMDCs, either untreated or treated with soluble SIINFEKL or NP-SIINFEKLNP 
conjugated peptides, were incubated with 5-(and 6-) carboxyfluorescein diacetate succinimidyl ester (CSFE) labeled OT-I T cells for 3 days. Proliferation of T cells was evaluated by flow cytometry. A representative flow cytometry histogram for each group is shown in Supporting Figure 2. As shown in Figure 4, BMDCs pulsed with soluble peptide at a concentration of $5 \mu \mathrm{g} / \mathrm{mL}$ were able to induce proliferation of cognate $\mathrm{CD} 8^{+} \mathrm{T}$ cells. In comparison, much enhanced $\mathrm{T}$ cell proliferation was observed for BMDCs treated with NP conjugated peptide, which indicates higher priming and activation of $\mathrm{CD} 8^{+} \mathrm{T}$ cells. CSIINFEKL conjugated to PRINT NPs via the longer cleavable linker resulted in approximately $95 \%$ of $\mathrm{T}$ cell growth, as compared to short cleavable linker (74.5\%) and soluble peptide (32.6\%). This is consistent with the enhanced antigen presentation by NPpeptide demonstrated above (Figure 4).

\subsection{Maturation of BMDCs by CpG ODN Conjugated PEG Hydrogels}

It is well-known that activation of naive T cells and development of multiple effector functions depends not only on recognition of MHC-I-peptide complex on APCs by TCRs but also on a second signal from engagement of costimulation receptors. Concurrent delivery of adjuvants has been shown to promote the second signals, further drive clonal expansion of naive $\mathrm{T}$ cells, and aid in their differentiation into armed effector $\mathrm{T}$ cells. ${ }^{17}$ The CD40 ligand and CD28 expressed on T cell surface bind to costimulatory molecules CD40 and CD80 on the surface of DCs, respectively. CD40 provides signals for activation, while CD80 provides signals for proliferation. The ability of PRINT NPs to deliver CpG ODN to provide costimulatory signals was tested in BMDCs. BMDCs were incubated with soluble $\mathrm{CpG}$ ODN or NP-CpG for $18 \mathrm{~h}$. After incubation, cells were analyzed for expression of CD80 and CD40 via flow cytometry. Expressions of costimulatory molecules were presented as a ratio of mean fluorescent intensity (MFI) to untreated cells. Treatment with $\mathrm{CpG}$ conjugated PRINT NPs at $1 \mu \mathrm{g} / \mathrm{mL}$ or $10 \mu \mathrm{g} / \mathrm{mL}$ concentrations induced upregulation of CD40 and CD80 on BMDCs as compared to untreated cells, as potently as soluble CpG. Therefore, the functionality of $\mathrm{CpG}$ is well retained during conjugation to nanoparticles. No upregulation of either marker was found when BMDCs were treated with CSIINFEKL conjugated NPs. Lack of response indicates the limitation of delivering antigen alone for maturation of BMDCs. CD40 and CD80 were both upregulated when CpG ODN were combined with antigenic CSIINFEKL peptide either via co-conjugation of CpG ODN and SIINFEKL on a single NP or when delivered on separate NPs (NP-CpG + NP-peptide), indicating the helper effect of adjuvant in the presence of antigen (Figure 5A,B).

\subsection{Induction of IFN- $\gamma$ Producing SIINFEKL Specific CD8 ${ }^{+}$T Cells in Mice}

After evaluating the efficiency of antigen presentation and maturation of BMDCs as well as OT-I T cell proliferation, PRINT NP subunit vaccines were analyzed for their efficacy to induce IFN- $\gamma$ producing antigen specific T cells in mice. Frequency of antigen-specific IFN$\gamma$ producing T cells in spleens of mice 7 days postimmunization was evaluated ex vivo by ELISPOT. First we evaluated whether co-conjugation of antigen and adjuvant are necessary by vaccinating mice with NP-SPDP-CSIINFEKL + NP-SPDP-CpG and NP-SPDPCSIINFEKL-CpG. We found that mice treated with NPs co-conjugated to antigenic peptide and $\mathrm{CpG}$ induced significantly higher $\mathrm{CD} 8^{+} \mathrm{T}$ cell response as compared to mice treated with separately conjugated NPs (Supporting Figure 3). Similar results were also reported by 
Schlosser et al. when they coencapsulated TLR ligands CpG or poly I:C and antigen in the same delivery system. ${ }^{52}$ Next we tested both the vaccine formulations for their ability to induce IFN- $\gamma$ producing $\mathrm{CD} 8^{+} \mathrm{T}$ cells. As shown in Figure 6A, there is a significant difference in induction of IFN $\gamma$ producing $\mathrm{CD} 8^{+} \mathrm{T}$ cells when mice were immunized with NP-SPDP-CSIINFEKL-CpG and NP-PEG(2k)OPSS-CSIINFEKL-CpG as compared to mice receiving a mixture of soluble antigen and adjuvant. Co-conjugation of adjuvant and antigen resulted in 10 times higher induction of IFN- $\gamma$ producing T cells as compared to NPs conjugated to antigen alone. IFN- $\gamma$ producing $\mathrm{T}$ cell response was minimum in case of negative control-blank PRINT NPs.

Secretion of IFN- $\gamma$ by antigen-specific $\mathrm{CD} 8^{+} \mathrm{T}$ cells into culture medium upon restimulation over 3 days was also examined by ELISA. Similar to T cell frequency analysis, the bulk production of IFN- $\gamma$ was also significantly higher for mice treated with NP formulations with co-conjugated peptide and adjuvant as compared to NP conjugated with just antigen, or soluble antigen and adjuvant (Figure 6B), again confirming the importance of codelivery of $\mathrm{CpG}$ adjuvant for IFN- $\gamma$ production.

\subsection{In Vivo CTL Response in Mice after Immunization with SIINFEKL and CpG Co- conjugated NPs}

Induction of CTLs is critical in generating an antitumor immune response. We evaluated PRINT NP subunit vaccines for their ability to induce CTLs through an in vivo CTL assay. ${ }^{46}$ Fifteen days after immunizations with mixture of soluble SIINFEKL and soluble $\mathrm{CpG}$ or NP-SPDP-CSIINFEKL-CpG or NP-PEG(2k)OPSS-CSIINFEKL-CpG, mice were adoptively transferred with SIINFEKL pulsed, CSFE ${ }^{\text {hi }}$ and control nonpulsed, $\mathrm{CSFE}^{\mathrm{lo}}$ target cells. On day 16, peptide pulsed and nonpulsed target cells in mouse spleens were differentiated by flow cytometry by two distinct population with high and low CFSE fluorescence (R5 and R4, respectively in Figure 7A-D). CSFE ${ }^{\text {hi }}$ population was decreased for peptide pulsed cells in mice immunized with a mixture of soluble peptide and soluble CpG (Figure 7B), NP-SPDP-CSIINFEKL-CpG (Figure 7C), and NP-PEG(2k)OPSSCSIINFEKL-CpG (Figure 7D). Moreover, the percentage of OVA specific cell killing was 90\% for mice treated with NP-PEG (2k) OPSS-CSIINFEKL-CpG, which is significantly higher than for mice treated with soluble antigen with soluble adjuvant (35\%) and NPSPDP-CSIINFEKL-CpG ODN (50\%) (Figure 7E). Results from these assays reveal that the longer linker is more efficient at in vivo target cell killing as compared to short linker.

\section{DISCUSSION}

Here we have shown (i) successful co-conjugation via reduction sensitive linkers of model antigenic peptide-SIINFEKL and CpG ODN to hydrogel NPs; (ii) delivery of CSIINFEKL via NPs to DCs that induced cross-presentation of SIINFEKL via MHC-I protein molecules and subsequently stimulated in vitro proliferation of OT-I T cells; (iii) delivery of CpG ODN via NPs provided 'adjuvanted' effect by inducing maturation of DCs as demonstrated by upregulation of CD80 and CD40; (iv) codelivery of CSIINFEKL and CpG ODN induced IFN $-\gamma$ producing robust $\mathrm{CD} 8^{+} \mathrm{T}$ cells; and (v) codelivery of CSIINFEKL and $\mathrm{CpG}$ ODN by 
reduction sensitive hydrogel system elicited potent CTLs that kill antigen specific target cells.

Within the past decade PRINT NPs have evolved into a unique delivery platform for various agents such as chemotherapeutics, fluorescent dyes, quantum dots, siRNA, and proteins. ${ }^{48,53-55}$ Due to the versatility of the PRINT platform, it has been employed to study the impact of various particle parameters in a biological system such as biodistribution of intravenously administered NPs as well as lymphatic trafficking of particles after intramuscular administration. ${ }^{56,57}$ Utilizing immunologically inert materials to mimic size, shape, and surface functionality of pathogens, PRINT provides an excellent platform to engineer subunit vaccines investigating various combinations of antigens and adjuvants to tune the immune response. ${ }^{58}$ Galloway et al. showed enhanced humoral response when mice were treated with trivalent influenza protein adsorbed cationic PLGA PRINT particles. ${ }^{59} \mathrm{In}$ an effort to induce mucosal immune response, Fromen et al. showed higher antibody titers of ovalbumin protein when delivered via intranasal immunization by PRINT hydrogels. ${ }^{50}$ Building upon this platform, herein we have presented the first PRINT system to induce potent CTL response by codelivering antigenic peptides and CpG ODN through reduction sensitive linkers.

Disulfide linkers have been widely used in antibody drug conjugates (ADCs) to allow for release of chemotherapeutic drugs in intracellular reductive environment and delivering antigenic proteins. ${ }^{60}$ Swartz lab and Hubbell lab have utilized disulfide chemistry to deliver model protein OVA as well as TAA peptide, Trp-2 via nanoparticles for the induction of in vivo immune response. They have shown induction of potent effector and memory $\mathrm{CD} 8^{+} \mathrm{T}$ cell responses for the inhibition of tumor growth. ${ }^{61-64}$ Others have also shown higher humoral and cellular response by disulfide conjugated OVA via polymeric nanoparticles. ${ }^{26,65}$ One advantage of this technique is that triggered release of the cargo only happens upon cellular internalization, due to the presence of various reductive enzymes in the endosome, lysosome, and cytosol. Therefore, employing reduction sensitive linkers to conjugate CpG ODN and SIINFEKL to NPs, we were able to deliver $\mathrm{CpG}$, resulting in stimulation of TLR- 9 and the triggered release of costimulatory molecules to enhance T cell activation, while also delivering SIINFEKL, to be cross-presented to the surface of APCs (vacuolar pathway). ${ }^{5}$ More experimental studies are required to understand the mechanism of NP uptake, trafficking, and antigen release.

Employing peptide antigens has many advantages including cost-effective, enhanced safety, specificity, and stability. Short peptides for MHC-I/HLA binding domains can be readily synthesized in large quantities. Using defined peptide epitopes allows for the generation of very specific arms of effector $\mathrm{T}$ cells without the health risk of inducing autoimmune or adverse reactions which may occur in response to whole protein antigens. ${ }^{66}$ Moreover, peptides can be chemically modified to improve their solubility, stability, and antigenicity. In our studies, the cysteine modification added to the peptide for conjugation purposes did not interfere with MHC I binding to SIINFEKL. However, ensuring that peptide modification does not alter MHC binding will need to be investigated for each unique application to confirm that the appropriate antigen/peptide is being presented. Clinical application of peptide vaccine requires matching of patients' HLA class I alleles to CTL epitopes to be 
able to induce T cell response. Multiple strategies, like multivalent peptide cocktail, hybrid peptides, and long peptides, have been adopted in recent clinical trials to enhance the applicability of peptide vaccines ${ }^{67}$ Nanoparticle-based delivery platform with versatility in peptide association like ours would be able to help simultaneous delivery of multiple antigenic peptides.

Polyethylene glycol (PEG) is extensively used in biomedicine and cosmetics due to its biocompatibility. It is widely acknowledged that acrylate-derivatized PEG (PEGDA) hydrogels undergo slow degradation in vivo due to either hydrolysis of end group acrylate esters or oxidation of the ether backbone. ${ }^{68-70}$ Making PRINT nanoparticles with poly(ethylene glycol) diacrylate (PEGDA) allows us to tune many physicochemical parameters. Another important parameter of PRINT hydrogel vaccine design is the positive surface charge provided by AEM in the composition. Cationic formulations enhance NP cellular internalization and endosomal escape thereby delivering cargo in the reductive environment of cytosol. ${ }^{48,49,58}$ Being able to take advantage of these cellular events should favor antigen cross presentation through the classical pathway. Neumann et al. has also reported inflammasome activation by cationic charged particles alone, which may potentially provide adjuvanticity and contribute to the high potency of our particle vaccines. ${ }^{71,72}$ Additionally, positively charged particles remain trapped at the injection site because of collagen fibers and negatively charged proteins (glycosaminoglycans) of extracellular matrix $(\mathrm{ECM}) .{ }^{73}$ Our previous study suggested that $80 \times 80 \times 320 \mathrm{~nm}$ cationic particles have minimal lymphatic drainage. ${ }^{57}$ Thus, our NP vaccines most likely rely on the uptake by tissue resident DCs at the injection site for antigen presentation, such as migratory $\mathrm{CD}_{103^{+}}$DCs in peripheral tissues, a subset of DCs very potent in antigen cross presentation. ${ }^{5}$ These results demonstrate the ability to perform well-controlled mechanistic studies to investigate the effect of optimizing PRINT particulate vaccine parameters in terms of immune cell targeting, APC uptake/activation, and nanoparticle vaccine efficacy.

\section{CONCLUSION}

In summary, we have investigated the use of an engineered PEG hydrogel subunit vaccine to harness the power of our own immune system to generate CTLs to validate this approach in the fight against cancer. We have designed and developed a model platform NP subunit vaccine to codeliver antigenic peptide and CpG ODN. These NPs were successfully internalized and processed by BMDCs, resulting in BMDC maturation, subsequent crosspresentation of antigenic peptide, and induction of potent antigen-specific $\mathrm{T}$ cells. Taken together, results from this study provided a highly specific and effective platform to develop vaccines against infectious disease and cancer.

\section{Supplementary Material}

Refer to Web version on PubMed Central for supplementary material.

\section{Acknowledgments}

The authors thank Dr. Ashish Pandya for the synthesis of HP4A, Dr. Jason Whitmire for the support in scientific discussion, Dr. Amar S. Kumbhar for support with NP imaging, and the University of North Carolina Animal 
Studies Core for their assistance with animal experiments. This work was supported by Liquidia Technologies, the Carolina Center for Cancer Nanotechnology Excellence (U54CA151652), and by the University Cancer Research Fund.

\section{References}

1. Rappuoli R, Mandl CW, Black S, De Gregorio E. Vaccines for the twenty-first century society. Nat Rev Immunol. 2011; 11(12):865-72. [PubMed: 22051890]

2. Moyle PM, Toth I. Modern subunit vaccines: development, components, and research opportunities. Chem Med Chem. 2013; 8(3):360-76. [PubMed: 23316023]

3. http://www.fda.gov/BiologicsBloodVaccines/Vaccines/ApprovedProducts/ucm093833.htm.

4. Brito LA, O'Hagan DT. Designing and building the next generation of improved vaccine adjuvants. J Controlled Release. 2014; 190:563-79.

5. Joffre OP, Segura E, Savina A, Amigorena S. Cross-presentation by dendritic cells. Nat Rev Immunol. 2012; 12(8):557-69. [PubMed: 22790179]

6. Neefjes J, Ovaa H. A peptide's perspective on antigen presentation to the immune system. Nat Chem Biol. 2013; 9(12):769-75. [PubMed: 24231618]

7. Black M, Trent A, Tirrell M, Olive C. Advances in the design and delivery of peptide subunit vaccines with a focus on toll-like receptor agonists. Expert Rev Vaccines. 2010; 9(2):157-73. [PubMed: 20109027]

8. Bachmann MF, Jennings GT. Vaccine delivery: a matter of size, geometry, kinetics and molecular patterns. Nat Rev Immunol. 2010; 10(11):787-96. [PubMed: 20948547]

9. Kapadia CH, Perry JL, Tian S, Luft JC, DeSimone JM. Nanoparticulate immunotherapy for cancer. J Controlled Release. 2015; 219:167-80.

10. Yuba E, Kojima C, Harada A, Tana, Watarai S, Kono K. pH-Sensitive fusogenic polymer-modified liposomes as a carrier of antigenic proteins for activation of cellular immunity. Biomaterials. 2010; 31(5):943-51. [PubMed: 19850335]

11. Flanary S, Hoffman AS, Stayton PS. Antigen delivery with poly(propylacrylic acid) conjugation enhances MHC-1 presentation and T-cell activation. Bioconjugate Chem. 2009; 20(2):241-8.

12. Demento SL, Cui W, Criscione JM, Stern E, Tulipan J, Kaech SM, Fahmy TM. Role of sustained antigen release from nanoparticle vaccines in shaping the $\mathrm{T}$ cell memory phenotype. Biomaterials. 2012; 33(19):4957-64. [PubMed: 22484047]

13. Diwan M, Tafaghodi M, Samuel J. Enhancement of immune responses by co-delivery of a CpG oligodeoxynucleotide and tetanus toxoid in biodegradable nanospheres. J Controlled Release. 2002; 85(1-3):247-62.

14. Silva AL, Rosalia RA, Sazak A, Carstens MG, Ossendorp F, Oostendorp J, Jiskoot W. Optimization of encapsulation of a synthetic long peptide in PLGA nanoparticles: low-burst release is crucial for efficient CD8(+) T cell activation. Eur J Pharm Biopharm. 2013; 83(3):33845. [PubMed: 23201055]

15. Moon JJ, Suh H, Bershteyn A, Stephan MT, Liu H, Huang B, Sohail M, Luo S, Um SH, Khant H, Goodwin JT, Ramos J, Chiu W, Irvine DJ. Interbilayer-crosslinked multilamellar vesicles as synthetic vaccines for potent humoral and cellular immune responses. Nat Mater. 2011; 10(3):24351. [PubMed: 21336265]

16. Zhu Y, Meng W, Gao H, Hanagata N. Hollow Mesoporous Silica/Poly(l-lysine) Particles for Codelivery of Drug and Gene with Enzyme-Triggered Release Property. J Phys Chem C. 2011; 115(28):13630-13636.

17. Janeway, CA., Jr, Travers, P., Walport, M., et al. Immunobiology: The Immune System in Health and Disease. 5. Garland Science; New York: 2001.

18. Kasturi SP, Skountzou I, Albrecht RA, Koutsonanos D, Hua T, Nakaya HI, Ravindran R, Stewart S, Alam M, Kwissa M, Villinger F, Murthy N, Steel J, Jacob J, Hogan RJ, Garcia-Sastre A, Compans R, Pulendran B. Programming the magnitude and persistence of antibody responses with innate immunity. Nature. 2011; 470(7335):543-7. [PubMed: 21350488] 
19. Beletskii A, Galloway A, Rele S, Stone M, Malinoski F. Engineered PRINT((R)) nanoparticles for controlled delivery of antigens and immunostimulants. Hum Vaccines Immunother. 2014; 10(7): 1908-13.

20. Singh M, O’Hagan D. Advances in vaccine adjuvants. Nat Biotechnol. 1999; 17(11):1075-1081. [PubMed: 10545912]

21. Sarti F, Perera G, Hintzen F, Kotti K, Karageorgiou V, Kammona O, Kiparissides C, BernkopSchnurch A. In vivo evidence of oral vaccination with PLGA nanoparticles containing the immunostimulant monophosphoryl lipid A. Biomaterials. 2011; 32(16):4052-7. [PubMed: 21377204]

22. de Titta A, Ballester M, Julier Z, Nembrini C, Jeanbart L, van der Vlies AJ, Swartz MA, Hubbell JA. Nanoparticle conjugation of $\mathrm{CpG}$ enhances adjuvancy for cellular immunity and memory recall at low dose. Proc Natl Acad Sci U S A. 2013; 110(49):19902-7. [PubMed: 24248387]

23. Verheul RJ, Slutter B, Bal SM, Bouwstra JA, Jiskoot W, Hennink WE. Covalently stabilized trimethyl chitosan-hyaluronic acid nanoparticles for nasal and intradermal vaccination. J Controlled Release. 2011; 156(1):46-52.

24. De Koker S, Cui J, Vanparijs N, Albertazzi L, Grooten J, Caruso F, De Geest BG. Engineering Polymer Hydrogel Nanoparticles for Lymph Node-Targeted Delivery. Angew Chem, Int Ed. 2016; 55(4):1334-9.

25. Zou Y, Xie L, Carroll S, Muniz M, Gibson H, Wei WZ, Liu H, Mao G. Layer-by-layer films with bioreducible and non-bioreducible polycations for sequential DNA release. Biomacromolecules. 2014; 15(11):3965-75. [PubMed: 25360688]

26. Keller S, Wilson JT, Patilea GI, Kern HB, Convertine AJ, Stayton PS. Neutral polymer micelle carriers with $\mathrm{pH}$-responsive, endosome-releasing activity modulate antigen trafficking to enhance CD8(+) T cell responses. J Controlled Release. 2014; 191:24-33.

27. Lebel ME, Chartrand K, Leclerc D, Lamarre A. Plant Viruses as Nanoparticle-Based Vaccines and Adjuvants. Vaccines (Basel, Switz). 2015; 3(3):620-37.

28. Gratton SE, Ropp PA, Pohlhaus PD, Luft JC, Madden VJ, Napier ME, DeSimone JM. The effect of particle design on cellular internalization pathways. Proc Natl Acad Sci U S A. 2008; 105(33): 11613-8. [PubMed: 18697944]

29. Waite CL, Roth CM. PAMAM-RGD conjugates enhance siRNA delivery through a multicellular spheroid model of malignant glioma. Bioconjugate Chem. 2009; 20(10):1908-16.

30. York AW, Huang F, McCormick CL. Rational design of targeted cancer therapeutics through the multiconjugation of folate and cleavable siRNA to RAFT-synthesized (HPMA-s-APMA) copolymers. Biomacromolecules. 2010; 11(2):505-14. [PubMed: 20050670]

31. Cohen BA, Bergkvist M. Targeted in vitro photodynamic therapy via aptamer-labeled, porphyrinloaded virus capsids. J Photochem Photobiol, B. 2013; 121:67-74. [PubMed: 23524248]

32. Chu TC, Marks JW 3rd, Lavery LA, Faulkner S, Rosenblum MG, Ellington AD, Levy M. Aptamer:toxin conjugates that specifically target prostate tumor cells. Cancer Res. 2006; 66(12): 5989-92. [PubMed: 16778167]

33. Lee JS, Green JJ, Love KT, Sunshine J, Langer R, Anderson DG. Gold, poly(beta-amino ester) nanoparticles for small interfering RNA delivery. Nano Lett. 2009; 9(6):2402-6. [PubMed: 19422265]

34. Kim HR, Kim IK, Bae KH, Lee SH, Lee Y, Park TG. Cationic solid lipid nanoparticles reconstituted from low density lipoprotein components for delivery of siRNA. Mol Pharmaceutics. 2008; 5(4):622-31.

35. Bagalkot V, Gao X. siRNA-aptamer chimeras on nanoparticles: preserving targeting functionality for effective gene silencing. ACS Nano. 2011; 5(10):8131-9. [PubMed: 21936502]

36. Mao HQ, Roy K, Troung-Le VL, Janes KA, Lin KY, Wang Y, August JT, Leong KW. ChitosanDNA nanoparticles as gene carriers: synthesis, characterization and transfection efficiency. $\mathrm{J}$ Controlled Release. 2001; 70(3):399-421.

37. Slutter B, Soema PC, Ding Z, Verheul R, Hennink W, Jiskoot W. Conjugation of ovalbumin to trimethyl chitosan improves immunogenicity of the antigen. J Controlled Release. 2010; 143(2): 207-14. 
38. Slutter B, Bal SM, Que I, Kaijzel E, Lowik C, Bouwstra J, Jiskoot W. Antigen-adjuvant nanoconjugates for nasal vaccination: an improvement over the use of nanoparticles? Mol Pharmaceutics. 2010; 7(6):2207-15.

39. Sheng KC, Kalkanidis M, Pouniotis DS, Esparon S, Tang CK, Apostolopoulos V, Pietersz GA. Delivery of antigen using a novel mannosylated dendrimer potentiates immunogenicity in vitro and in vivo. Eur J Immunol. 2008; 38(2):424-36. [PubMed: 18200633]

40. Chen N, Wei M, Sun Y, Li F, Pei H, Li X, Su S, He Y, Wang L, Shi J, Fan C, Huang Q. Selfassembly of poly-adenine-tailed CpG oligonucleotide-gold nanoparticle nanoconjugates with immunostimulatory activity. Small. 2014; 10(2):368-75. [PubMed: 23963797]

41. Singh N, Agrawal A, Leung AK, Sharp PA, Bhatia SN. Effect of nanoparticle conjugation on gene silencing by RNA interference. J Am Chem Soc. 2010; 132(24):8241-3. [PubMed: 20518524]

42. Jones SW, Roberts RA, Robbins GR, Perry JL, Kai MP, Chen K, Bo T, Napier ME, Ting JP, Desimone JM, Bear JE. Nanoparticle clearance is governed by Th1/Th2 immunity and strain background. J Clin Invest. 2013; 123(7):3061-73. [PubMed: 23778144]

43. Mutwiri GK, Nichani AK, Babiuk S, Babiuk LA. Strategies for enhancing the immunostimulatory effects of CpG oligodeoxynucleotides. J Controlled Release. 2004; 97(1):1-17.

44. Madaan A, Verma R, Singh AT, Jain SK, Jaggi M. A stepwise procedure for isolation of murine bone marrow and generation of dendritic cells. J Microbiol Methods. 2014; 1:1.

45. Quah BJ, Warren HS, Parish CR. Monitoring lymphocyte proliferation in vitro and in vivo with the intracellular fluorescent dye carboxyfluorescein diacetate succinimidyl ester. Nat Protoc. 2007; 2(9):2049-56. [PubMed: 17853860]

46. Ingulli E. Tracing tolerance and immunity in vivo by CFSE-labeling of administered cells. Methods Mol Biol. 2007; 380:365-76. [PubMed: 17876106]

47. Frohlich E. The role of surface charge in cellular uptake and cytotoxicity of medical nanoparticles. Int J Nanomed. 2012; 7:5577-91.

48. Ma D, Tian S, Baryza J, Luft JC, DeSimone JM. Reductively Responsive Hydrogel Nanoparticles with Uniform Size, Shape, and Tunable Composition for Systemic siRNA Delivery in Vivo. Mol Pharmaceutics. 2015; 12(10):3518-26.

49. Dunn SS, Tian S, Blake S, Wang J, Galloway AL, Murphy A, Pohlhaus PD, Rolland JP, Napier ME, DeSimone JM. Reductively responsive siRNA-conjugated hydrogel nanoparticles for gene silencing. J Am Chem Soc. 2012; 134(17):7423-30. [PubMed: 22475061]

50. Fromen CA, Rahhal TB, Robbins GR, Kai MP, Shen TW, Luft JC, DeSimone JM. Nanoparticle surface charge impacts distribution, uptake and lymph node trafficking by pulmonary antigenpresenting cells. Nanomedicine. 2016; 12:677. [PubMed: 26656533]

51. Storkus WJ, Zeh HJ 3rd, Salter RD, Lotze MT. Identification of T-cell epitopes: rapid isolation of class I-presented peptides from viable cells by mild acid elution. J Immunother. 1993; 14(2):94103.

52. Schlosser E, Mueller M, Fischer S, Basta S, Busch DH, Gander B, Groettrup M. TLR ligands and antigen need to be coencapsulated into the same biodegradable microsphere for the generation of potent cytotoxic T lymphocyte responses. Vaccine. 2008; 26(13):1626-37. [PubMed: 18295941]

53. Hampton MJ, Templeton JL, DeSimone JM. Direct patterning of CdSe quantum dots into sub-100 nm structures. Langmuir. 2010; 26(5):3012-5. [PubMed: 20102224]

54. Roberts RA, Eitas TK, Byrne JD, Johnson BM, Short PJ, McKinnon KP, Reisdorf S, Luft JC, DeSimone JM, Ting JP. Towards programming immune tolerance through geometric manipulation of phosphatidylserine. Biomaterials. 2015; 72:1-10. [PubMed: 26325217]

55. Kelly JY, DeSimone JM. Shape-specific, monodisperse nanomolding of protein particles. J Am Chem Soc. 2008; 130(16):5438-9. [PubMed: 18376832]

56. Reuter KG, Perry JL, Kim D, Luft JC, Liu R, DeSimone JM. Targeted PRINT Hydrogels: The Role of Nanoparticle Size and Ligand Density on Cell Association, Biodistribution, and Tumor Accumulation. Nano Lett. 2015; 15(10):6371-8. [PubMed: 26389971]

57. Mueller SN, Tian S, DeSimone JM. Rapid and Persistent Delivery of Antigen by Lymph Node Targeting PRINT Nanoparticle Vaccine Carrier To Promote Humoral Immunity. Mol Pharmaceutics. 2015; 12(5):1356-65. 
58. Roberts RA, Shen T, Allen IC, Hasan W, DeSimone JM, Ting JP. Analysis of the murine immune response to pulmonary delivery of precisely fabricated nano- and microscale particles. PLoS One. 2013; 8(4):e62115. [PubMed: 23593509]

59. Galloway AL, Murphy A, DeSimone JM, Di J, Herrmann JP, Hunter ME, Kindig JP, Malinoski FJ, Rumley MA, Stoltz DM, Templeman TS, Hubby B. Development of a nanoparticle-based influenza vaccine using the PRINT technology. Nanomedicine. 2013; 9(4):523-31. [PubMed: 23178283]

60. Saito G, Swanson JA, Lee KD. Drug delivery strategy utilizing conjugation via reversible disulfide linkages: role and site of cellular reducing activities. Adv Drug Delivery Rev. 2003; 55(2):199_ 215.

61. Jeanbart L, Ballester M, de Titta A, Corthesy P, Romero P, Hubbell JA, Swartz MA. Enhancing efficacy of anticancer vaccines by targeted delivery to tumor-draining lymph nodes. Cancer Immunol Res. 2014; 2(5):436-47. [PubMed: 24795356]

62. Hirosue S, Kourtis IC, van der Vlies AJ, Hubbell JA, Swartz MA. Antigen delivery to dendritic cells by poly(propylene sulfide) nanoparticles with disulfide conjugated peptides: Crosspresentation and T cell activation. Vaccine. 2010; 28(50):7897-906. [PubMed: 20934457]

63. Eby JK, Dane KY, O’Neil CP, Hirosue S, Swartz MA, Hubbell JA. Polymer micelles with pyridyl disulfide-coupled antigen travel through lymphatics and show enhanced cellular responses following immunization. Acta Biomater. 2012; 8(9):3210-7. [PubMed: 22698945]

64. Stano A, Scott EA, Dane KY, Swartz MA, Hubbell JA. Tunable T cell immunity towards a protein antigen using polymersomes vs. solid-core nanoparticles. Biomaterials. 2013; 34(17):4339-46. [PubMed: 23478034]

65. Wilson JT, Keller S, Manganiello MJ, Cheng C, Lee CC, Opara C, Convertine A, Stayton PS. pHResponsive nanoparticle vaccines for dual-delivery of antigens and immunostimulatory oligonucleotides. ACS Nano. 2013; 7(5):3912-25. [PubMed: 23590591]

66. Slingluff CL. The Present and Future of Peptide Vaccines for Cancer: Single or Multiple, Long or Short, Alone or in Combination? Cancer J (Philadelphia, PA, U S). 2011; 17(5):343-350.

67. Yamada A, Sasada T, Noguchi M, Itoh K. Next-generation peptide vaccines for advanced cancer. Cancer Sci. 2013; 104(1):15-21. [PubMed: 23107418]

68. Browning MB, Cereceres SN, Luong PT, Cosgriff-Hernandez EM. Determination of the in vivo degradation mechanism of PEGDA hydrogels. J Biomed Mater Res, Part A. 2014; 102(12):424451.

69. Browning MB, Russell B, Rivera J, Hook M, Cosgriff-Hernandez EM. Bioactive hydrogels with enhanced initial and sustained cell interactions. Biomacromolecules. 2013; 14(7):2225-33. [PubMed: 23758437]

70. Browning MB, Cosgriff-Hernandez E. Development of a biostable replacement for PEGDA hydrogels. Biomacromolecules. 2012; 13(3):779-86. [PubMed: 22324325]

71. Neumann S, Burkert K, Kemp R, Rades T, Rod Dunbar P, Hook S. Activation of the NLRP3 inflammasome is not a feature of all particulate vaccine adjuvants. Immunol Cell Biol. 2014; 92(6):535-42. [PubMed: 24687021]

72. Sharp FA, Ruane D, Claass B, Creagh E, Harris J, Malyala P, Singh M, O'Hagan DT, Petrilli V, Tschopp J, O’Neill LA, Lavelle EC. Uptake of particulate vaccine adjuvants by dendritic cells activates the NALP3 inflammasome. Proc Natl Acad Sci U S A. 2009; 106(3):870-5. [PubMed: 19139407]

73. Zhan X, Tran KK, Shen H. Effect of the poly(ethylene glycol) (PEG) density on the access and uptake of particles by antigen-presenting cells (APCs) after subcutaneous administration. Mol Pharmaceutics. 2012; 9(12):3442-51. 


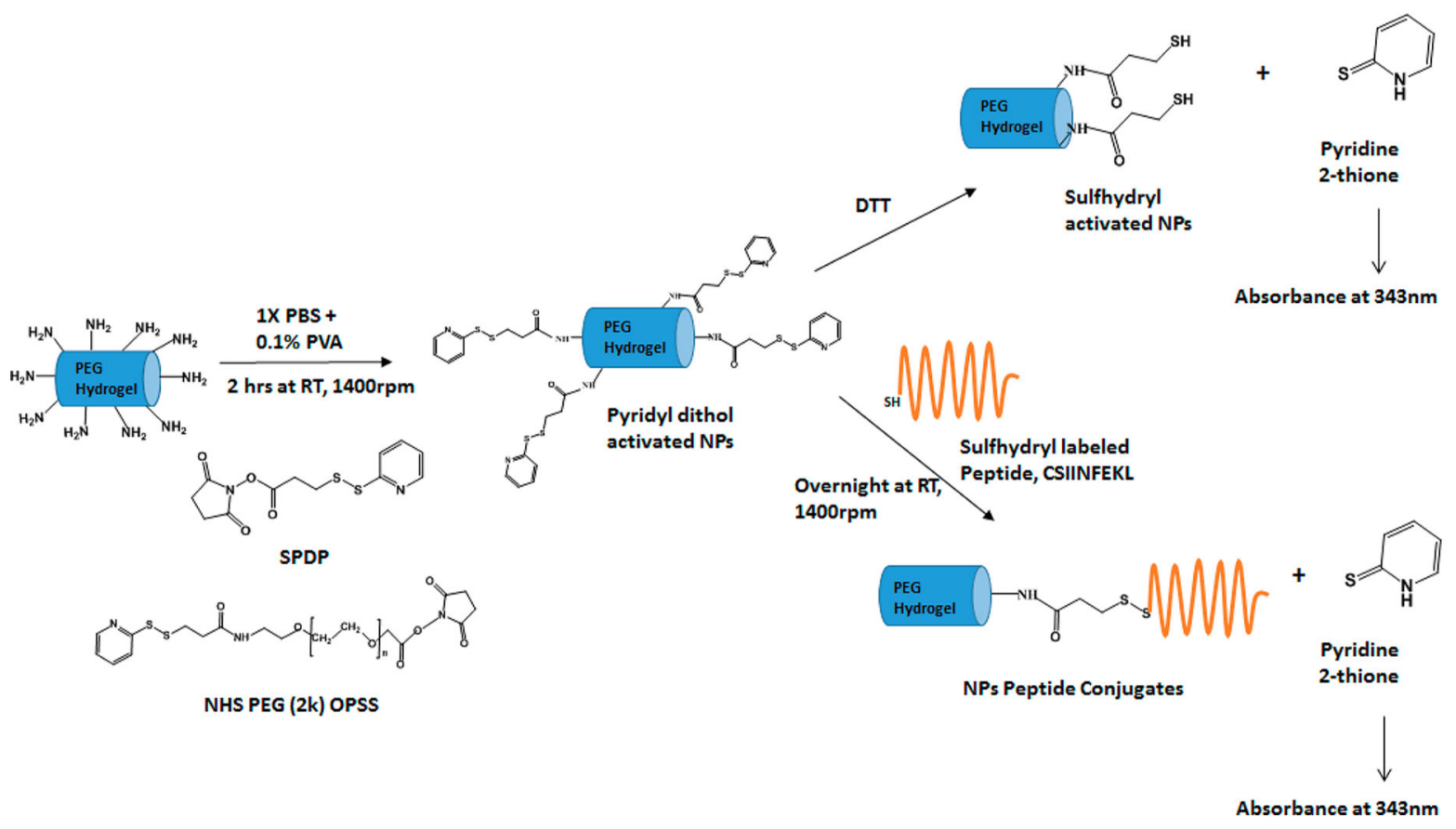

Figure 1.

Conjugation of cleavable linkers and cysteine labeled SIINFEKL to PEG hydrogels. PEG hydrogels were first modified with cleavable linkers SPDP or NHS-PEG(2k)-OPSS. NPlinker conjugation was evaluted through the release of pyridine-2-thione after incubation of NPs with DTT. Linker modified particles were incubated with CSIINFEKL, and peptide conjugation was evaluated through the release of pyridine-2-thione. 


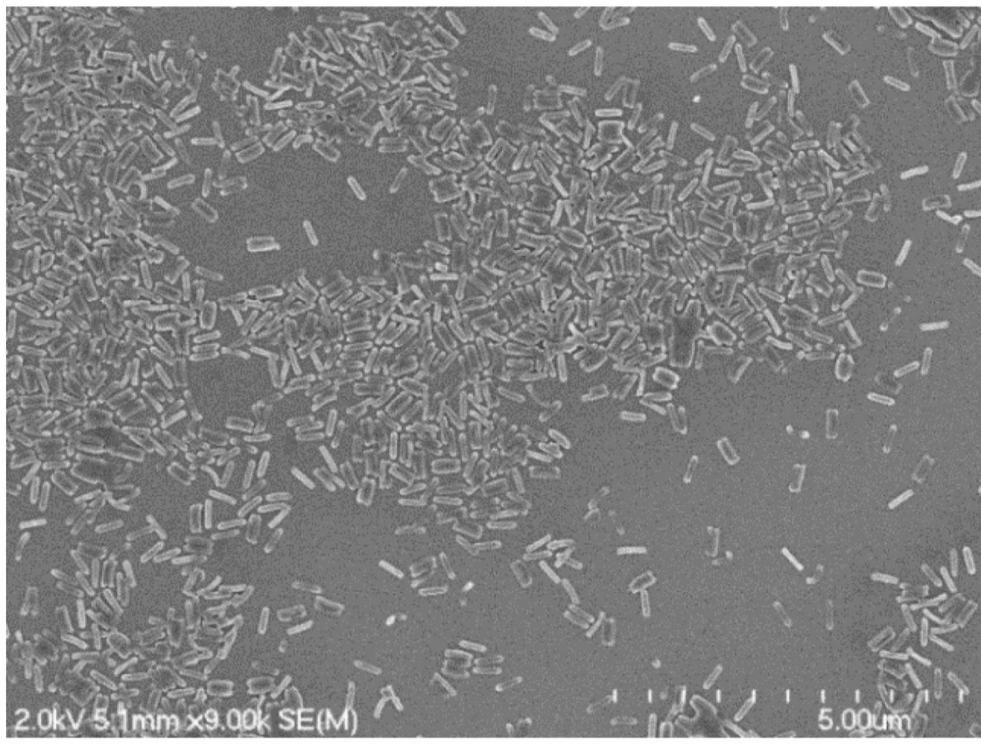

Figure 2.

Representative SEM image of $80 \times 320 \mathrm{~nm}$ PRINT subunit peptide vaccine. 

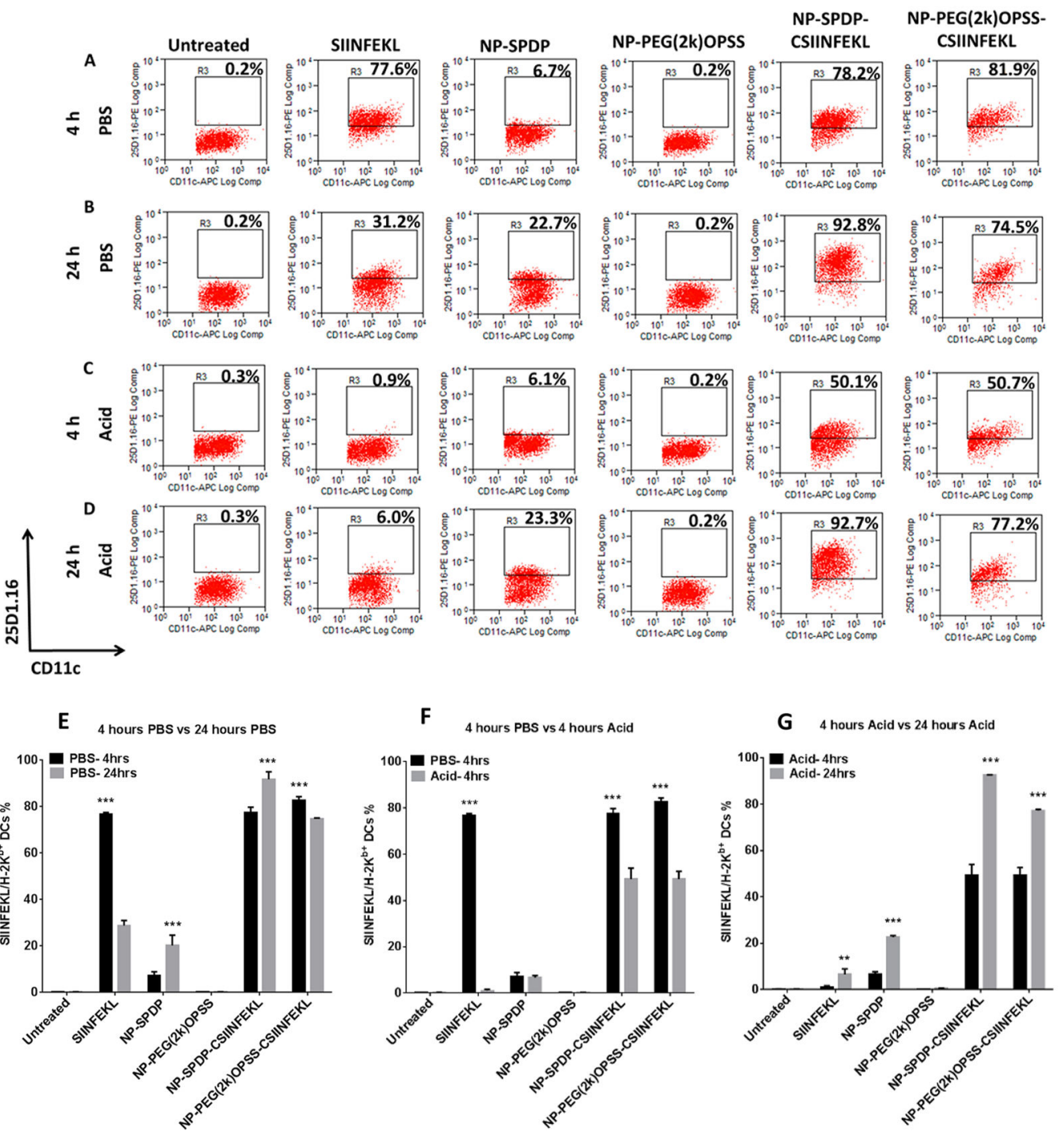

Figure 3.

Enhanced antigen presentation by NP-peptide in BMDCs. BMDCs were treated with different formulations for $4 \mathrm{~h}$ and washed with PBS (A), and incubated for another $20 \mathrm{~h}$ (B), or washed with acidic citrate-phosphate buffer $(\mathrm{pH} 3)(\mathrm{C})$, and incubated for another $20 \mathrm{~h}$ (D). Representative flow cytometry histogram for each group is shown in panels $\mathrm{A}$ to $\mathrm{D}$. The numbers in the histograms represent the percentage of $\mathrm{CD} 11 \mathrm{c}^{+}$dendritic cells that were positive for $\mathrm{p} / \mathrm{MHC}$ I. Quantitative analysis of data $(\mathrm{E}-\mathrm{G})$. Results are shown as mean $\pm \mathrm{SD}$, $n=3$. E-G, data were analyzed by two-way ANOVA, Tukey's post hoc analysis, ${ }^{*} p<0.01$, $* * * p<0.001$. 


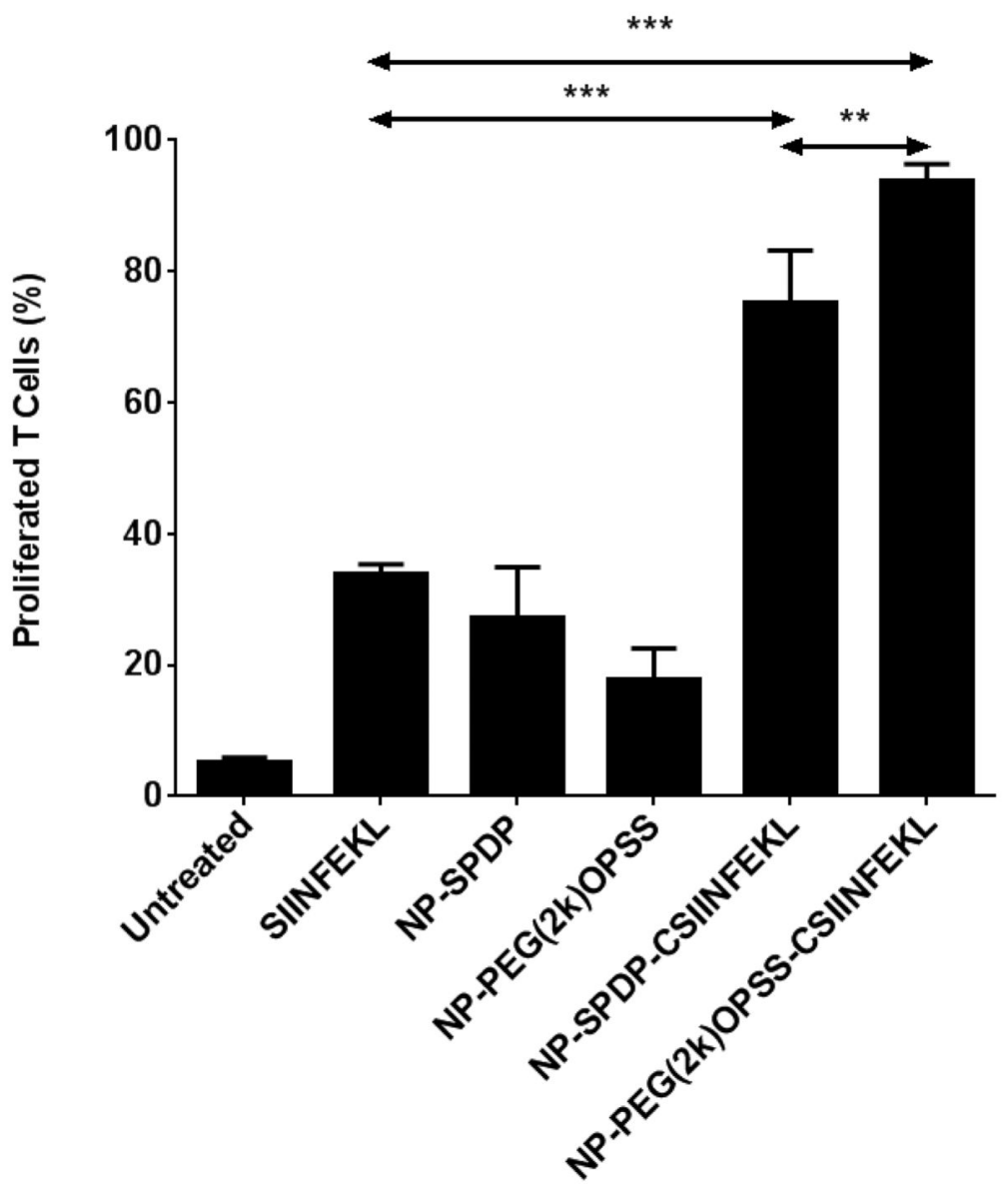

Figure 4.

T-cell proliferation assay. Peptide conjugated NPs induced higher T cell proliferation as compared to soluble peptide. Bone marrow derived dendritic cells (BMDCs) were incubated for $4 \mathrm{~h}$ with free peptide and nanoparticulate peptide conjugated via short and long cleavable linkers. Pulsed BMDCs were then incubated with CFSE-labeled OT-I CD ${ }^{+} \mathrm{T}$ cells for 3 days. T cells were surface stained, and proliferation of OT-I T cells was assessed by flow cytometry. Percentage of $\mathrm{T}$ cell proliferation after treatment with different formulations is shown in Figure 5. Results are shown as mean $\pm \mathrm{SD}, n=3$. Data were analyzed by one-way ANOVA, Bonferroni post hoc analysis, $* * p<0.01, * * * p<0.001$. 

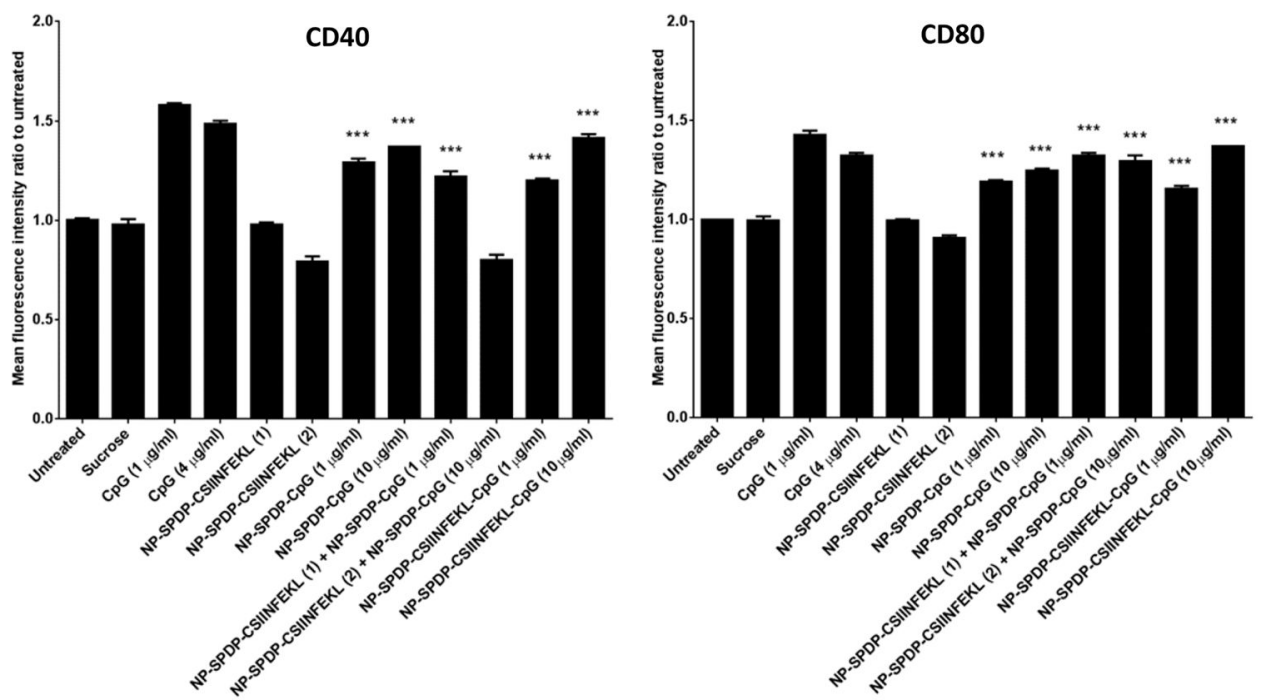

Figure 5.

Upregulation of maturation markers by NP-CpG on BMDCs. BMDCs were treated with various samples for $24 \mathrm{~h}$ with 1,4 , or $10 \mu \mathrm{g} / \mathrm{mL}$ of $\mathrm{CpG}$. Equivalent amounts of NPs were dosed in the case of NP-peptide. NP-SPDP-CSIINFEKL (1) has an equivalent dose of NPs to $1 \mu \mathrm{g} / \mathrm{mL}$ particulate $\mathrm{CpG}$, and NP-SPDP-CSIINFEKL (2) has an equivalent dose of NPs to $10 \mu \mathrm{g} / \mathrm{mL}$ particulate $\mathrm{CpG}$. The expression of costimulatory molecules was detected by flow cytometry analysis of fluorescence labeled CD40 and CD80 antibodies. Ratio of MFI from sample to MFI of untreated is plotted in panel A for CD40 and panel B for CD80. Results are shown here as mean $\pm \mathrm{SD}, n=3$. Data were analyzed by one-way ANOVA, Bonferroni post hoc analysis, $* * * p<0.001$. 

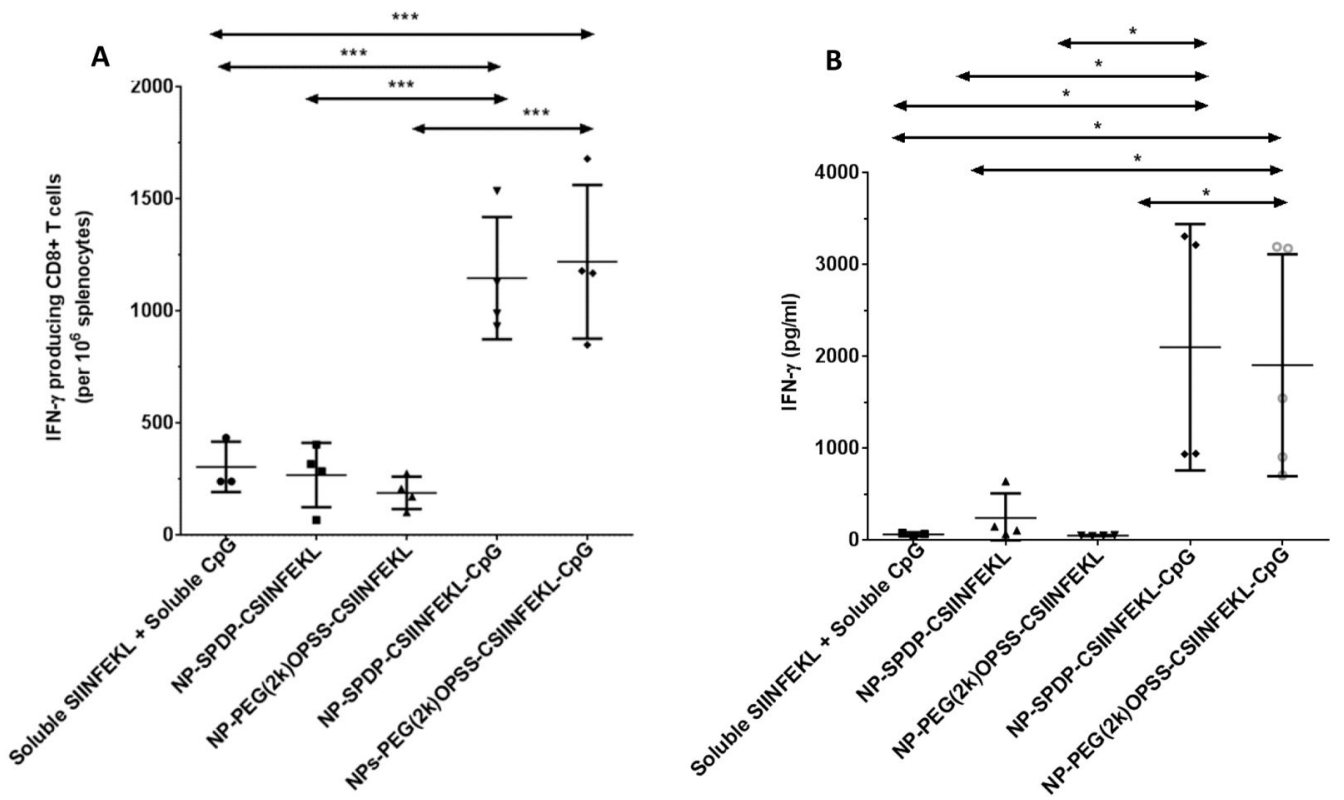

Figure 6.

Induction of IFN- $\gamma$ producing SIINFEKL specific CD8 ${ }^{+} \mathrm{T}$ cells in spleen. Mice were immunized with various samples containing $100 \mu \mathrm{g}$ of peptide and/or $20 \mu \mathrm{g}$ of $\mathrm{CpG}$ via sc injection in the left flank. One week later, splenocytes were isolated and restimulated with SIINFEKL for $20 \mathrm{~h}$ for IFN- $\gamma$ ELISPOT assay (A), or for $72 \mathrm{~h}$ for ELISA analysis of secreted IFN $-\gamma$ in medium (B). Results are shown as mean $\pm \mathrm{SD}, n=4$. Data were analyzed by one-way ANOVA, Holm-Sidak's multiple comparison test, ${ }^{*} p<0.05, * * * p<0.001$. 


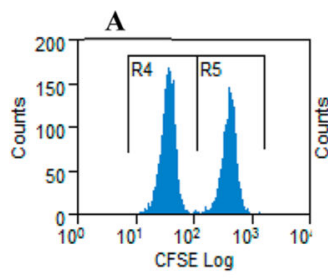

Untreated

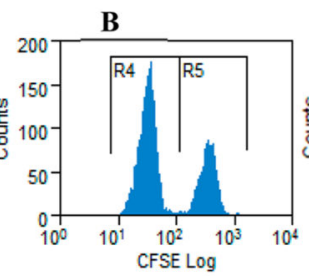

Soluble SIINFEKL + Soluble CpG

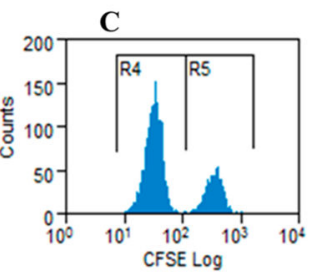

NPS-SPDPCSIINFEKL-CpG
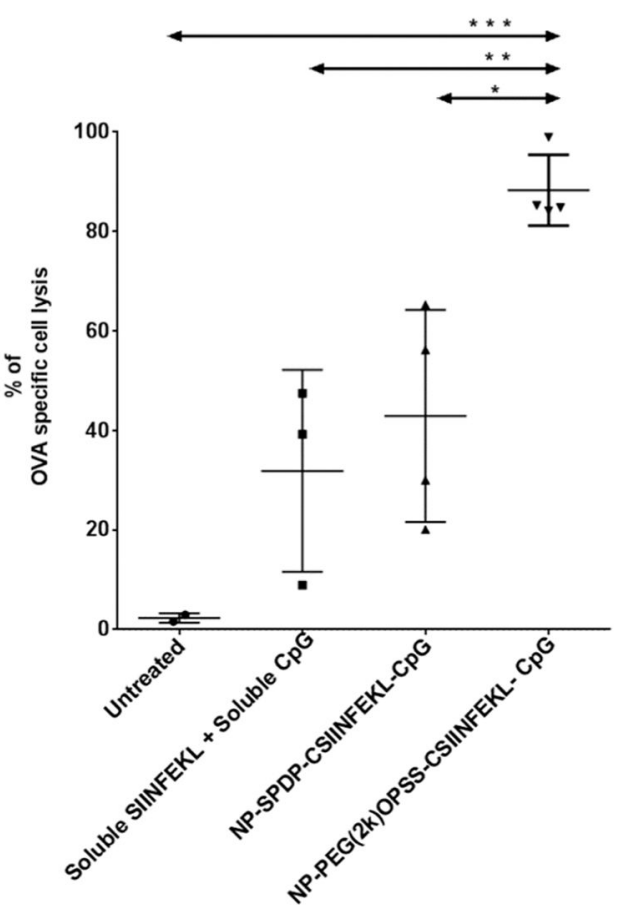

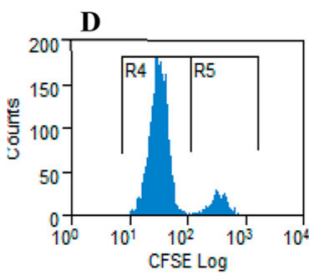

NPs-PEG (2k) OPSS- CSIINFEKL$\mathrm{CpG}$

Figure 7.

In vivo CTL response after vaccination with model peptide hydrogel cancer vaccine. NPsPEG(2k)OPSS-CSIINFEKL-CpG is more effective at killing target cells compared to NPsSPDP-CSIINFEKL-CpG. Purified OT-I CD8 ${ }^{+} \mathrm{T}$ cells were adoptively transferred into C57BL/6 mice. Two days later, mice were kept (a) untreated or immunized with either (b) soluble SIINFEKL + soluble CpG or (c) NPs-SPDP-CSIINFEKL-CpG or (d) NPs-PEG OPSS-CSIINFEKL-CpG. Fifteen days later, CFSE labeled wild type splenocytes (non peptide pulsed CFSE ${ }^{\text {hi }}$ and peptide pulsed CFSE $^{\text {lo }}$, 1:1) were iv transferred into immunized mice. After $20 \mathrm{~h}$, splenocytes were isolated and population of target cells was determined by flow cytometry. Representative histogram analysis of untreated (A), soluble SIINFEKL + soluble CpG (B), NPs-SPDP-CSIINFEKL-CpG (C), and NPs-PEG(2k)OPSS-CSIINFEKLCpG (D). Quantitation of specific lysis from flow cytometry data in A-D (E). Results are shown here as mean $\pm \mathrm{SD}, n=4$. Data were analyzed by one-way anova, Holm-Sidak's multiple comparison test, $* p<0.05, * * p<0.01$, *** $p<0.001$. 


\section{Table 1}

Gradient Method for HPLC Run

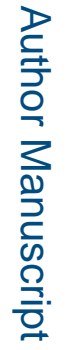

\begin{tabular}{lrrc}
\hline & \multicolumn{2}{c}{ \% of mobile phase } & \\
\cline { 2 - 3 } time, $\boldsymbol{m i n}$ & A & B & flow rate (mL/min) \\
\hline 0 & 100 & 0 & 2 \\
5 & 100 & 0 & 2 \\
25 & 5 & 95 & 2 \\
28 & 5 & 95 & 2 \\
30 & 100 & 0 & 2
\end{tabular}

文

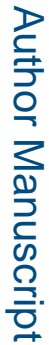

竞

Mol Pharm. Author manuscript; available in PMC 2017 November 30. 


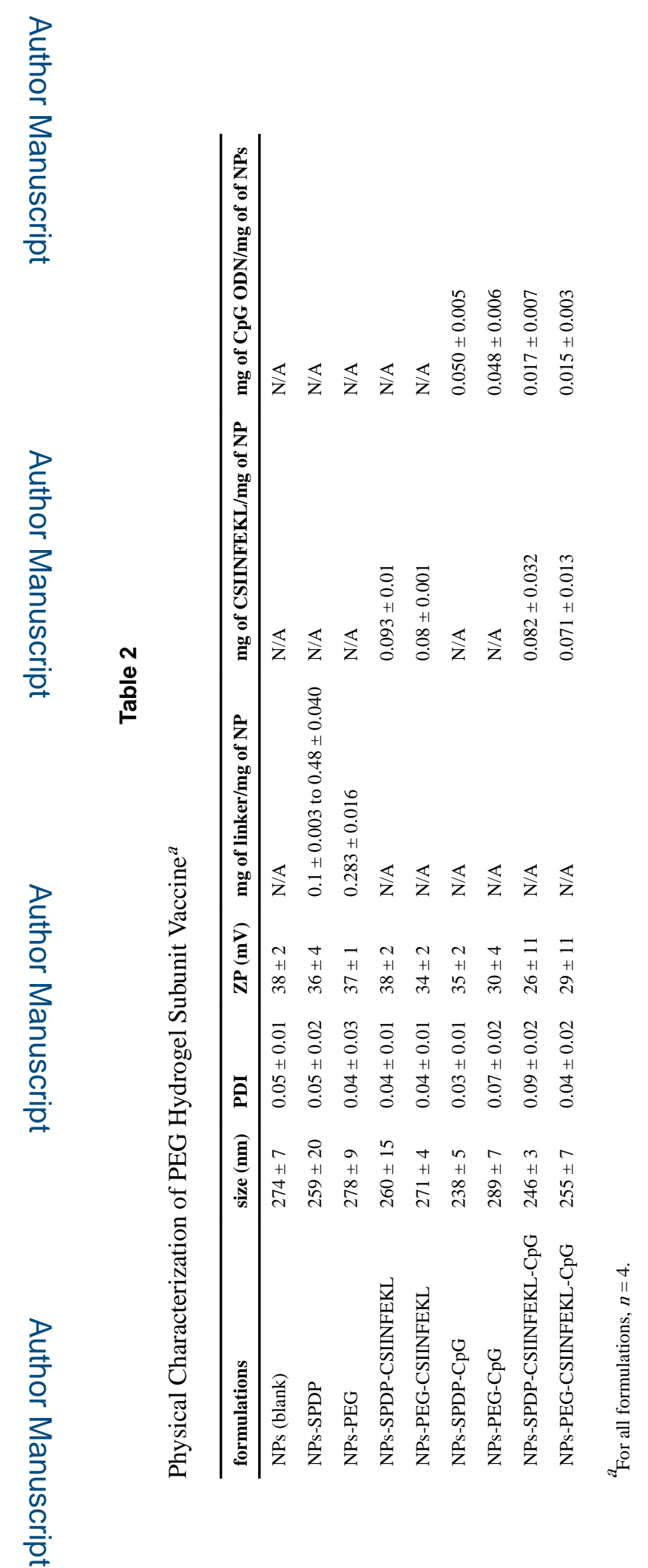

Mol Pharm. Author manuscript; available in PMC 2017 November 30. 